\title{
Reactive fronts in chemically heterogeneous porous media: Experimental and modeling investigation of pyrite oxidation
}

\author{
Battistel, Maria; Muniruzzaman, Muhammad; Onses, Felix; Lee, Jonghyun; Rolle, Massimo
}

Published in:

Applied Geochemistry

Link to article, DOI:

10.1016/j.apgeochem.2018.10.026

Publication date:

2019

Document Version

Peer reviewed version

Link back to DTU Orbit

Citation (APA):

Battistel, M., Muniruzzaman, M., Onses, F., Lee, J., \& Rolle, M. (2019). Reactive fronts in chemically heterogeneous porous media: Experimental and modeling investigation of pyrite oxidation. Applied Geochemistry, 100, 77-89. https://doi.org/10.1016/j.apgeochem.2018.10.026

\section{General rights}

Copyright and moral rights for the publications made accessible in the public portal are retained by the authors and/or other copyright owners and it is a condition of accessing publications that users recognise and abide by the legal requirements associated with these rights.

- Users may download and print one copy of any publication from the public portal for the purpose of private study or research.

- You may not further distribute the material or use it for any profit-making activity or commercial gain

- You may freely distribute the URL identifying the publication in the public portal 


\section{Accepted Manuscript}

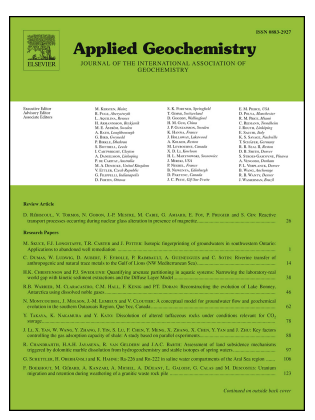

Reactive fronts in chemically heterogeneous porous media: Experimental and modeling investigation of pyrite oxidation

Maria Battistel, Muhammad Muniruzzaman, Felix Onses, Jonghyun Lee, Massimo Rolle

PII: S0883-2927(18)30312-3

DOI: https://doi.org/10.1016/j.apgeochem.2018.10.026

Reference: $\quad$ AG 4214

To appear in: $\quad$ Applied Geochemistry

Received Date: 27 June 2018

Revised Date: 31 October 2018

Accepted Date: 31 October 2018

Please cite this article as: Battistel, M., Muniruzzaman, M., Onses, F., Lee, J., Rolle, M., Reactive fronts in chemically heterogeneous porous media: Experimental and modeling investigation of pyrite oxidation, Applied Geochemistry (2018), doi: https://doi.org/10.1016/j.apgeochem.2018.10.026.

This is a PDF file of an unedited manuscript that has been accepted for publication. As a service to our customers we are providing this early version of the manuscript. The manuscript will undergo copyediting, typesetting, and review of the resulting proof before it is published in its final form. Please note that during the production process errors may be discovered which could affect the content, and all legal disclaimers that apply to the journal pertain. 


\section{Reactive fronts in chemically heterogeneous porous media:}

\section{Experimental and modeling investigation of pyrite oxidation}

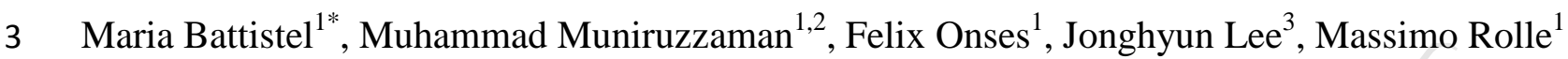

$4{ }^{1}$ Department of Environmental Engineering, Technical University of Denmark, 2800 Lyngby, 5 Denmark.

$6 \quad{ }^{2}$ Geological Survey of Finland, 70150 Kuopio, Finland

$7{ }^{3}$ Department of Civil and Environmental Engineering and Water Resources Research Center, 8 University of Hawaii, Honolulu, Hawaii 96822, USA

$9 \quad$ * Corresponding author: marbat@env.dtu.dk

Keywords: pyrite oxidation, reactive transport modeling, chemical heterogeneity, reactive fronts, flow-through experiments

\section{Abstract}

The spatial distribution of reactive minerals in subsurface porous media is an important control for groundwater quality. In this study we investigate pyrite oxidation reactive fronts in chemically heterogeneous porous media by combining laboratory experiments and reactive transport modeling. We performed experiments in different setups including batch, 1-D column, and 2-D flow-through systems. The flow-through experiments were performed in physically homogenous but chemically heterogeneous domains with embedded reactive pyrite inclusions at different spatial locations and with different concentrations. The setups were initially maintained under anoxic conditions and subsequently flushed with an inflowing oxic solution. A non-invasive optode technique was used for high-resolution monitoring of oxygen. This allowed us to capture the dynamics of the reactive oxygen fronts in the 1-D columns and in the 2-D flow-through chamber. Water quality analyses of 
the products of pyrite oxidation, iron $(\mathrm{Fe})$ and sulfur $(\mathrm{S})$, were also carried out in the different setups. The concentration of these species released in the $1-\mathrm{D}$ columns (up to $6.2 \times 10^{-5} \mathrm{~mol} / \mathrm{L} \mathrm{Fe}$ and $13.7 \times 10^{-5} \mathrm{~mol} / \mathrm{L} \mathrm{S}$ ) and in the 2-D setup (up to $3 \times 10^{-6} \mathrm{~mol} / \mathrm{L} \mathrm{Fe}$ and $9 \times 10^{-6} \mathrm{~mol} / \mathrm{L} \mathrm{S}$ ) could be quantitatively related to the consumption of oxygen (up to $1.9 \times 10^{-4} \mathrm{~mol} / \mathrm{L}$ consumed in the 1 -D and 2-D setups). The reaction rates were found to be different between the setups and dependent on the spatial location and concentration of the pyrite inclusions.

A modeling approach coupling 1-D and 2-D transport codes with the geochemical simulator PHREEQC is proposed to simulate the spatial and temporal dynamics of oxygen transport, the kinetics of pyrite oxidative dissolution, and the changes in water quality in the chemically heterogeneous flow-through setups. The model allowed the quantitative interpretation of the experimental results and represents a valuable tool to capture the coupling between multidimensional transport and geochemical reactions both in laboratory and in field scale applications.

\section{Introduction}

Geochemical heterogeneities in subsurface formations exert a primary control on the chemistry of water bodies (Appelo and Postma, 2005; Battistel et al., 2016; Zhu and Schwartz, 2011). The presence of reactive minerals and their spatial distribution affect important biogeochemical processes such as dissolution and precipitation reactions (Li et al., 2014; Manaka and Takeda, 2016; Salehikhoo and Li, 2015; Shi et al., 2013; Soltanian et al., 2015; Wen and Li, 2018) as well as the fate and transport of toxic elements in groundwater (Englert et al., 2009; Li et al., 2011; Steefel et al., 2005). The impact of reactive minerals on groundwater quality is critical in areas where redox conditions may be altered due to both natural processes, subsurface contamination, and engineering applications. For instance in aquifers where managed aquifer recharge is used as a strategy to 
improve drinking water supply, the injection of oxidizing water into an anoxic groundwater system triggers a series of geochemical reactions that are responsible for changes in the chemical conditions and composition in the subsurface (Descourvières et al., 2010b; Prommer and Stuyfzand, 2005). Also groundwater pumping and subsequent dewatering (e.g., during groundwater supply or mining activity) can lead to a change in the subsurface redox conditions. The decrease of piezometric levels allows the atmospheric oxygen to penetrate into sediments layers containing reactive minerals and thus promotes the mobilization of heavy metals and metalloids (Andersen et al., 2001; Kinniburgh et al., 1994; Larsen and Postma, 1997). As shown in comparative studies on intact core sediments, pyrite oxidation plays a predominant role in oxygen consumption and can be a faster process than microbially-mediated organic matter degradation and siderite oxidation (Descourvières et al., 2010a; Hartog et al., 2002). The oxidation of pyrite is indeed a crucial reaction for the chemistry of water resources, and often the oxidative dissolution of pyrite can have adverse effects on water quality. The release of trace elements in groundwater aquifers (Neil et al., 2014; Walker et al., 2006; Ziegler et al., 2017), and the acidification of surface and groundwater, are two major adverse impacts of pyrite oxidation (Gerke et al., 2001, 1998). Activities, such as mining and ore processing, can exacerbate the problems related to the oxidative dissolution of pyrite, producing acid drainage often heavily enriched with high concentration of metals and metalloids (Blowes et al., 2003; Galán et al., 2003; Sánchez España et al., 2005; Stollenwerk, 1994). The oxidation of pyrite can also play a role in nitrate migration in sandy aquifers (Jessen et al., 2017; Postma et al., 1991) and in nickel mobilization (Larsen and Postma, 1997). Furthermore, the oxidative dissolution of arsenic-bearing pyrite has been identified as one of the main causes of arsenic release in natural and managed aquifers (Appelo and Postma, 2005; Jones and Pichler, 2007; Kocar et al., 2008; Lazareva et al., 2015; Price and Pichler, 2006; Prommer and Stuyfzand, 2005; Schreiber et al., 2000; Wallis et al., 2010). 
71 This study aims to investigate the role of chemical heterogeneity on reactive transport in porous media and to provide a high-resolution dataset, obtained under well-controlled conditions, which can be used as a benchmark for validation of reactive transport simulators. The latter are fundamental tools to understand complex geochemical reactions in subsurface porous media and for the quantitative upscaling of important biogeochemical processes such as mineral precipitation and dissolution in field scale reactive transport scenarios (e.g., Jung and Navarre-Sitchler, 2018; Wen and $\mathrm{Li}, 2018$ ). We performed a detailed investigation of pyrite oxidation in saturated porous media by carrying out laboratory experiments in different setups including batch, 1-D column, and 2-D flow-through systems. We focused on the impact of geochemical heterogeneities and, in a number of flow-through experiments, we embedded reactive pyrite inclusions in a sandy matrix with identical grain size, thus creating physically homogeneous but chemically heterogeneous media. Oxic water was flushed through the initially anoxic media and the transport of oxygen, its consumption due to the oxidative dissolution of pyrite, and the impact of the reaction on the quality of the pore water solution were monitored at high-spatial and temporal resolution. A reactive transport modeling approach coupling 1-D and 2-D transport codes with the geochemical simulator PHREEQC (Parkhurst and Appelo, 2013) was used to quantitatively interpret the experimental observations. Advection, dispersion and kinetic gas partitioning of oxygen with residual entrapped gas were the main physical processes described in the transport codes, whereas the reaction network, including a kinetic description of pyrite oxidation, was implemented in PHREEQC. 


\section{Material and Methods}

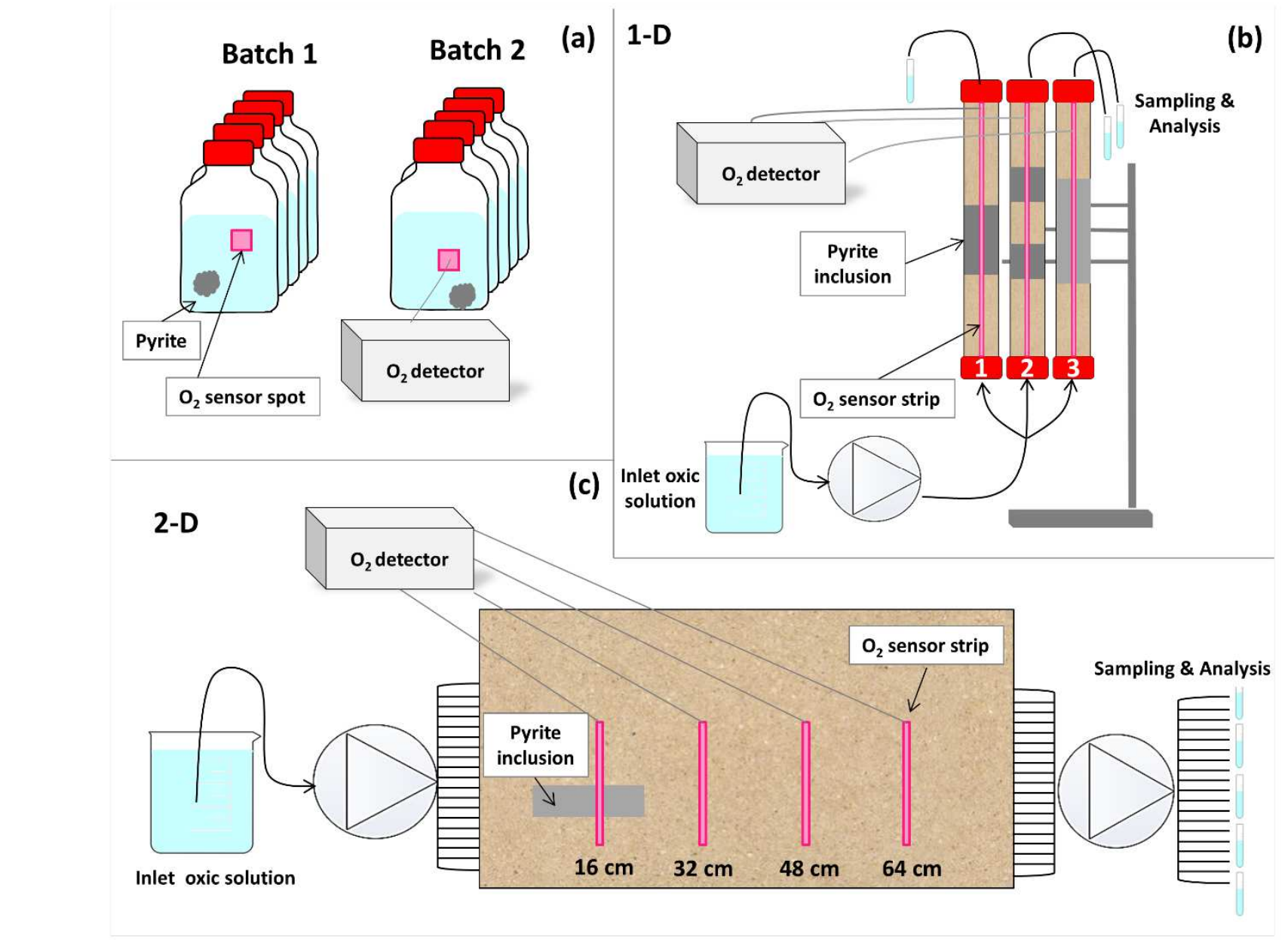

\subsection{Experimental setups}

In this work, the oxidative dissolution of pyrite was experimentally investigated in batch, 1-D and 2-D setups. A schematic overview of the three setups is given in Fig. 1. All the experiments were performed in a temperature controlled room at $20^{\circ} \mathrm{C}$.

5 96
97

Fig. 1. Experimental laboratory setups for the investigation of pyrite oxidation: (a) batch experiments, (b) 1-D column experiments, (c) 2-D flow-through experiments. Different colors of the inclusions represent their different composition, dark gray: pure pyrite inclusion, light gray: pyrite mixed with sand. 
The pyrite used in these experiments was provided from Mexico by Ward's Science. The mineral was prepared for the experiments following the procedure described in Walker et al. (2006) for arsenopyrite. Pyrite was crushed in a mortar and sieved to obtain a grain size between $125 \mu \mathrm{m}$ and $250 \mu \mathrm{m}$. After sieving, the pyrite was rinsed five times with ethanol $50 \%(\mathrm{v} / \mathrm{v})$ with sonication cycles of three minutes each and the supernatant was removed by decantation. After the sonication cycles, the pyrite was dried under $\mathrm{N}_{2}$. The mineral was then treated with $\mathrm{HCl}(37 \%)$ for five minutes, rinsed three times with distilled water for three minutes and with ethanol $50 \%(\mathrm{v} / \mathrm{v})$ for one minute. Finally, the pyrite was dried under a constant $\mathrm{N}_{2}$ flow and preserved under anoxic conditions until used in the experiments. To avoid microbial contamination, all glassware and materials that contacted the minerals were autoclaved. The average chemical formula of the mineral was determined to be $\mathrm{Fe}_{1} \mathrm{~S}_{1.72}$, based on X-ray fluorescence (XRF) analysis (Spectro XRF-XEPOS X-ray fluorescence spectrometer). Iron K-edge extended X-ray absorption fine structure (EXAFS) spectroscopy was conducted at Stanford Synchrotron Radiation Lightsource, (SSRL) and revealed that Fe exists entirely as pyrite and no iron oxides were detected onto the mineral surface (Fig. S1; Supporting Information). The sand used for packing the flow-through setups (Euroquartz GmbH) was washed four times with $\mathrm{HCl}(37 \%)$, rinsed with water, and then dried for $>24 \mathrm{~h}$ at $100^{\circ} \mathrm{C}$.

During the experiments the oxygen consumption and the propagation of conservative and reactive oxygen fronts were monitored using a sensor-based non-invasive approach. The sensors used in this study allowed us to measure oxygen concentrations in the three different setups at high spatial and temporal resolution. $\mathrm{O}_{2}$ measurements could be taken directly inside the porous media by applying a non-invasive optode technique (PreSens GmbH, Germany; e.g., Haberer et al., 2011). Spots and strips of a luminophore oxygen sensitive polymer were glued into the inner walls of the experimental setups. The sensor was excited by a modulated light via an optic fiber from the outside of the walls, and since the molecular oxygen has the property of quenching the luminescence 
emitted by the excited luminophore, $\mathrm{O}_{2}$ content was estimated by measuring the luminescence intensity and lifetime (Klimant and Wolfbeis, 1995). This technique has been applied in porous media to investigate the exchange of $\mathrm{O}_{2}$ across the capillary fringe (Haberer et al., 2015b, 2012), transverse mixing (Rolle et al., 2012, 2010), aerobic degradation of organic contaminants and oxygen dynamics in the hyporheic zone (Bauer et al., 2009; Jost et al., 2011; Vieweg et al., 2013).

The technique allows to quantify oxygen concentrations with an accuracy ranging between \pm 0.002 $\mathrm{mg} / \mathrm{L}$ and $\pm 0.16 \mathrm{mg} / \mathrm{L}$ depending on the oxygen concentration, and has a detection limit of 0.015 $\mathrm{mg} / \mathrm{L}$. Further details on the measurement technique and an illustration of the $\mathrm{O}_{2}$ sensors and the optic fiber in the 2-D flow-through setup is provided in the Supplementary Material (Figure S2).

The products of pyrite oxidation, total iron $(\mathrm{Fe})$, total sulfur $(\mathrm{S})$ and $\mathrm{pH}$, were analyzed in the different experimental setups. The samples for the measurements of total Fe and $\mathrm{S}$ were filtered through a $0.2 \mu \mathrm{m}$ filter and acidified with $3 \% \mathrm{HNO}_{3}$, and the analyses were performed with Inductively Coupled Plasma - Optical Emission Spectroscopy (ICP-OES) (Perkin Elmer Avio ${ }^{\mathrm{Tm}}$ 200). The $\mathrm{pH}$ was measured in the non-acidified samples with a Hach electrode PHC28101 (HACH Denmark).

\subsubsection{Batch experiments}

Batch experiments were performed to characterize the kinetics of the oxidative dissolution of pyrite by monitoring the consumption of oxygen and the formation of the reaction products. Two sets of batch experiments (Batch 1 and Batch 2) were prepared using glass bottles with a volume of 26.8 $\mathrm{mL}$ each. At the inner wall of each bottle an $\mathrm{O}_{2}$-sensitive sensor spot (PreSens $\mathrm{GmbH}$ ) was attached. The bottles were filled with $20.0 \mathrm{~mL}$ of oxic solution of $\mathrm{NaCl}(5 \mathrm{mM})$ in deionized water and $1.0 \mathrm{~g}$ of pyrite. The remaining headspace $(6.8 \mathrm{~mL})$ was initially filled with atmospheric air. At the beginning of the experiment the bottles were hermetically sealed with butyl/PTFE 20 mm caps. 
149 Each batch experiment consists of an array of 15 bottles and during the experiment all the bottles 150 were stirred continuously with a magnetic stirrer at two different velocities: $300 \mathrm{rpm}$ (Batch 1) and $151100 \mathrm{rpm}$ (Batch 2). Oxygen concentrations were measured every 24 hours with the non-invasive 152 optode technique described above. A blank replicate, consisting of a bottle with the same volume of 153 solution but with no pyrite was used to monitor the oxygen concentration in absence of reaction 154 throughout the entire experiments. For each batch experiment, two bottles were sampled and 155 156 157 158 sacrificed at different times (every $24 \mathrm{~h}$ for Batch 1 and at larger time intervals for Batch 2) and measurements of $\mathrm{O}_{2}, \mathrm{Fe}$, and $\mathrm{S}$ were performed; $\mathrm{pH}$ was measured at the beginning and at the end of each experiment. Figure 1a schematically illustrates the setup of the batch experiments.

\subsubsection{Column experiments}

Glass columns (length: $14.5 \mathrm{~cm}$; inner diameter: $1.7 \mathrm{~cm}$ ) were used to study pyrite oxidation in 1-D flow-through setups. Prior to the investigation of reactive transport, 1-D flow-through experiments were conducted to characterize $\mathrm{O}_{2}$ transport under conservative conditions (i.e., with no pyrite present in the system). A $10 \mathrm{~cm} \times 0.5 \mathrm{~cm} \mathrm{O}_{2}$ sensitive strip (SF-PSt3-NAU, PreSens GmbH) was glued into the inner wall of each column and the columns were then packed with fine silica sand (125-250 $\mu \mathrm{m})$ in the column previously filled with anoxic water, always keeping the water table above the porous media to minimize air entrapment (Haberer et al., 2012).

The reactive transport experiments were performed in three columns, in which different pyrite inclusions were embedded in the porous media. The grain size of the pyrite was the same of the surrounding sandy matrix $(125-250 \mu \mathrm{m})$, thus the column setups consisted of physically homogeneous but chemically heterogeneous porous media. In Column 1, a 4-cm inclusion of pure pyrite was located in the middle of the column. In Column 2, two 2-cm inclusions of pure pyrite were placed in the middle of the column at a distance of $2 \mathrm{~cm}$ from each other. Column 3 was 
packed with a single $6-\mathrm{cm}$ inclusion of pyrite mixed with sand (1:1 in mass) placed in the middle of the column. The initial bulk concentration of pyrite in Column 1 and Column 2 was $25.70 \mathrm{~mol} / \mathrm{L}_{\text {bulk }}$ while in Column 3 was $12.85 \mathrm{~mol} / \mathrm{L}_{\text {bulk }}$ (Table 1 ). The columns were sealed with two screw caps with silicon-polytetrafluoroethylene septa. Steady-state flow-through conditions were established in the three columns with a high-precision multi-channel peristaltic pump (Ismatec IPC-24, Ismatec, Glattburg, Switzerland). The initial anoxic conditions were reached inside the columns by flushing the porous media with an anoxic solution $\left(\mathrm{O}_{2}\right.$ concentration $\left.<0.1 \mathrm{mg} / \mathrm{L}\right)$, prepared using an anoxic gas generation sachet (Oxoid AnaeroGen 2.5L, Thermo Scientific). The experiment consisted in flushing oxic water through the initially anoxic reactive columns and was started by connecting the pump tubings with the oxic solution, a $5 \mathrm{mM} \mathrm{NaCl}$ solution equilibrated with atmospheric oxygen. The average seepage velocity was maintained at $1.5 \mathrm{~m} /$ day in all three columns. The propagation of the oxygen fronts in the different porous media was monitored by measuring high-resolution spatial profiles along the columns (2.5 mm spacing) as well as breakthrough near the outlet of each column $(x=11.75 \mathrm{~cm})$, with three fiber optic cables recording oxygen concentrations every five minutes throughout the duration of the experiments. Conventional sampling was also performed at the columns' outlets and effluents were collected for the measurement of total $\mathrm{Fe}, \mathrm{S}$ and $\mathrm{pH}$.

\subsubsection{2-D flow-through experiments}

The setup consists of a quasi two-dimensional flow-through chamber with inner dimensions of 80 $\mathrm{cm} \times 40 \mathrm{~cm} \times 0.5 \mathrm{~cm}$ (length $\times$ height $\times$ width). The walls of the chamber are made of transparent acrylic glass and were equipped with four $\mathrm{O}_{2}$ sensitive strips (SF-PSt3-NAU, PreSens GmbH) with dimensions of $20 \mathrm{~cm}$ by $1 \mathrm{~cm}$, glued in the inner-side of the chamber wall. The sensors strips were located at $16 \mathrm{~cm}, 32 \mathrm{~cm}, 48 \mathrm{~cm}$ and $64 \mathrm{~cm}$ from the inlet perpendicular to the flow direction. The chamber was filled with fine sand $(125-250 \mu \mathrm{m})$, following the wet-packing procedure described 
195 for the column setups. A rectangular reactive pyrite inclusion, with the same grain size of the

196

197 surrounding sandy matrix, was embedded in the chamber. The pyrite inclusion was created by mixing pure pyrite and sand (1:1 in mass) and had a length of $16 \mathrm{~cm}$ and a height of $4 \mathrm{~cm}$. The inclusion was placed at $5 \mathrm{~cm}$ from the inlet and at $10 \mathrm{~cm}$ from the bottom of the flow-through chamber. Two high-precision multichannel peristaltic pumps (Ismatec IPC-N24) connected to 19 ports $(1.2 \mathrm{~cm}$ spacing) at the inlet and at the outlet of the chamber (Fig. 1c) were used to create steady flow conditions throughout the duration of the experiment.

Similarly to the column experiments, the system was initially maintained under anoxic conditions (background $\mathrm{O}_{2}$ concentration $<0.1 \mathrm{mg} / \mathrm{L}$ ) obtained by flushing the system with an anoxic solution. At the beginning of the experiment, an inflowing oxic solution $(5 \mathrm{mM} \mathrm{NaCl}$ aqueous solution equilibrated with the atmospheric oxygen) was continuously injected into the chamber at a seepage velocity of $1.5 \mathrm{~m} /$ day.

High-resolution vertical $\mathrm{O}_{2}$ profiles were measured along the four sensor strips, located at different cross-sections. Measurements were repeated at various time intervals to monitor the dynamics of oxygen transport and consumption in the 2-D setup. When the oxygen concentrations approached steady state, effluent samples were also collected from the dense network of outlet ports and measurements of $\mathrm{pH}$, iron and sulfur were performed.

The physical properties, the initial, and the inlet concentrations of the solutions in the different laboratory experiments are listed in Table 1.

Table 1. Overview of the laboratory experiments including both initial and inlet concentrations of aqueous species and the physical properties for the laboratory setups.

\begin{tabular}{lccccc}
\hline Parameter & Batch & \multicolumn{3}{c}{ 1-D columns } & 2-D chamber \\
\cline { 2 - 6 } & $\mathbf{1 - 2}$ & $\mathbf{1}$ & $\mathbf{2}$ & $\mathbf{3}$ & \\
\cline { 2 - 6 } Physical properties & & & & & \\
Experiment duration [hours] & $170-333$ & 100 & 100 & 100 & 98 \\
Seepage velocity [m/day] & - & 1.5 & 1.5 & 1.5 & 1.5 \\
Grain size [mm] & $0.125-0.250$ & $0.125-0.250$ & $0.125-0.250$ & $0.125-0.250$ & $0.125-0.250$ \\
Porosity [-] & - & 0.38 & 0.38 & 0.38 & 0.38
\end{tabular}


Initial aqueous concentrations

$\mathrm{pH}$

$\begin{array}{ccccc}6.0 & 5.8 & 5.8 & 5.8 & 6.77 \\ 2.6 \times 10^{-4} & 3.0 \times 10^{-5} & 3.0 \times 10^{-5} & 3.0 \times 10^{-5} & 3.0 \times 10^{-5} \\ 5.0 \times 10^{-3} & 5.0 \times 10^{-3} & 5.0 \times 10^{-3} & 5.0 \times 10^{-3} & 5.0 \times 10^{-3} \\ 5.0 \times 10^{-3} & 5.0 \times 10^{-3} & 5.0 \times 10^{-3} & 5.0 \times 10^{-3} & 5.0 \times 10^{-3} \\ & & & & \\ 0.45^{*} & 25.70 & 25.70 & 12.85 & 12.85\end{array}$

$\mathrm{O}_{2}[\mathrm{~mol} / \mathrm{L}]$

$\mathrm{Na}^{+}[\mathrm{mol} / \mathrm{L}]$

$\mathrm{Cl}^{-}[\mathrm{mol} / \mathrm{L}]$

Solid phase

Concentration of pyrite $\left[\mathrm{mol} / \mathrm{L}_{\text {bulk }}\right]$

Inlet aqueous concentrations

$\mathrm{pH}$

$\mathrm{O}_{2}[\mathrm{~mol} / \mathrm{L}]$

$\mathrm{Na}^{+}[\mathrm{mol} / \mathrm{L}]$

5.8

$2.5 \times 10^{-4}$

5.8

5.8

5.2

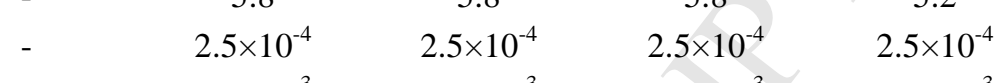

- $\quad 5.0 \times 10^{-3} \quad 5.0 \times 10^{-3} \quad 5.0 \times 10^{-3} \quad 5.0 \times 10^{-3}$

\subsection{Modeling approach}

\subsubsection{Chemical reaction framework}

To quantitatively evaluate the results obtained from the experiments, chemical reactions including

pyrite oxidation, the subsequent iron (hydr)oxides precipitation and the aqueous speciation were considered in the model. The oxidation of pyrite in the presence of oxygen releases iron and sulfate as main reaction products, and implies the consumption of $\mathrm{O}_{2}$ and the generation of acid (e.g., Appelo and Postma, 2005; Prommer and Stuyfzand, 2005; Rimstidt and Vaughan, 2003;

$$
\mathrm{FeS}_{1.72}+3.08 \mathrm{O}_{2}+0.72 \mathrm{H}_{2} \mathrm{O} \rightarrow \mathrm{Fe}^{2+}+1.72 \mathrm{SO}_{4}^{2-}+1.44 \mathrm{H}^{+}
$$

225 Upon the persistence of oxidizing condition, the released $\mathrm{Fe}$ (II) is further oxidized to Fe(III) and 226 can subsequently precipitate as described by the following reactions:

$$
\begin{aligned}
& \mathrm{Fe}^{2+}+0.25 \mathrm{O}_{2}+\mathrm{H}^{+} \rightarrow \mathrm{Fe}^{3+}+0.50 \mathrm{H}_{2} \mathrm{O} \\
& \mathrm{Fe}^{3+}+3 \mathrm{H}_{2} \mathrm{O}+\mathrm{H}^{+} \rightarrow \mathrm{FeOOH}(s)+3 \mathrm{H}^{+}
\end{aligned}
$$


Note that $\mathrm{FeOOH}(\mathrm{s})$ represents the precipitation of a solid Fe(III) phases. Both pyrite oxidation and $\mathrm{FeOOH}$ precipitation were simulated as kinetically-controlled reactions. For the oxidative dissolution of pyrite, we used the rate law proposed by Williamson and Rimstidt (1994), which is widely accepted in the literature and has been adopted by different authors investigating pyrite oxidation both in experimental and modeling studies (Fakhreddine et al., 2016; Jørgensen et al., 2008; Prommer and Stuyfzand, 2005; Vaclavkova et al., 2015) :

$$
R_{p y r}=\left(k\left[O_{2}\right]^{0.50}\left[H^{+}\right]^{-0.11}\right)\left(\frac{A_{p y r}}{V_{w}}\right)\left(\frac{m}{m_{0}}\right)^{0.67}\left(1-\Omega_{p y r}\right)
$$

where $R_{p y r}[\mathrm{~mol} / \mathrm{L} / \mathrm{s}]$ is the overall rate of reaction, $k\left[\mathrm{~mol} / \mathrm{m}^{2} / \mathrm{s}\right]$ the rate constant, and $\left[O_{2}\right]$ and $\left[H^{+}\right][\mathrm{mol} / \mathrm{L}]$ are the aqueous concentration of oxygen and protons. The last term represents the distance from equilibrium and $\Omega_{p y r}=I A P / K$ is the ratio of the ion activity product and the thermodynamic equilibrium constant. The term $A_{p y r} / V_{w}\left[\mathrm{~m}^{2} / \mathrm{L}\right]$ specifies the ratio of reactive surface area to the volume of solution, and the term $\left(\mathrm{m} / \mathrm{m}_{0}\right)^{0.67}$ accounts for the change in surface area resulting from the dissolution of pyrite being $m$ [mol] the unreacted pyrite content and $m_{0}$ [mol] the initial mineral content. We consider the surface area of the mineral and the volume of solution surrounding it as:

$$
\frac{A_{p y r}}{V_{w}}=\frac{A_{e}}{V_{w}} m_{0}
$$

241 where $A_{e}\left[\mathrm{~m}^{2} / \mathrm{g}\right]$ is the reactive surface area, considered as the specific surface area that effectively 242 reacts ( $\mathrm{Li}$ et al., 2014), which is typically defined as the total surface area per unit mass of the 243 mineral. In this study, we used the same value of the rate coefficient $\left(k=10^{-8.19} \mathrm{~mol} / \mathrm{m}^{2} / \mathrm{s}\right)$ as 244 reported by Williamson and Rimstidt (1994), whereas the ratio $A_{e} / V_{w}$ was considered as a fitting parameter. 
The precipitation of $\mathrm{FeOOH}$ was modeled with a simple rate law with an effective rate constant and

247 a term accounting for the distance from equilibrium:

$$
R_{\text {FeOOH }}=k_{\text {eff }}\left(1-\Omega_{\text {FeOOH }}\right)
$$

248

249

\subsubsection{Reactive transport}

A reactive transport description was implemented to simulate the propagation of oxygen fronts in the chemically heterogeneous flow-through porous media. The governing equations include the main physical and chemical processes occurring in the experimental setups. The considered transport processes include advection and dispersion, as well as the kinetic partitioning of oxygen between the aqueous and an entrapped gas phase. The latter process was found to be important to interpret the experimental results; in fact, although good care was taken to minimize air entrapment it was not possible to completely avoid it and a minor fraction of the pore space was occupied by entrapped gas. The gas phase influenced the oxygen transient transport behavior and led to the delay of the oxygen fronts compared to a conservative, non-partitioning solute. Such phenomena was observed in all the reactive flow-through experiments (both 1-D and 2-D) and additional column experiments without pyrite inclusions were run to further characterize oxygen partitioning. This process has been studied also by other authors who found that even a very small amount of entrapped gas causes a remarkable impact on oxygen transport and breakthrough (e.g., Donaldson et al., 1997). For the cases of reactive transport, the chemical reactions were implemented according to the framework described in the previous section and applied to evaluate the results of the batch setups. The governing mass conservation equations for reactive transport in multidimensional flowthrough systems can be expressed as: 


$$
\begin{aligned}
& \theta_{w} \frac{\partial c_{w, i}}{\partial t}+\theta_{g} \frac{\partial c_{g, i}}{\partial t}+\mathbf{q} \cdot\left(\nabla c_{w, i}\right)-\nabla \cdot\left(\theta_{w} \mathbf{D}_{i} \nabla c_{w, i}\right)=-\sum_{j=1}^{N_{j}} v_{i j} R_{j} \\
& \theta_{g} \frac{\partial c_{g, i}}{\partial t}=\lambda\left(H c_{w, i}-c_{g, i}\right)
\end{aligned}
$$

where Eq. [7] refers to reactive solute transport and partitioning of a volatile species within the mobile aqueous phase and Eq. [8] describes the mass transfer of the species between the immobile gas phase and mobile water phase, $c_{w, i}$ and $c_{g, i}[\mathrm{~mol} / \mathrm{L}]$ are the aqueous and gas phase concentrations of species $i$, respectively; whereas $\theta_{w}$ and $\theta_{g}[-]$ represent the volumetric water and gas content, respectively. $R_{j}[\mathrm{~mol} / \mathrm{L} / \mathrm{s}]$ and $v_{i j}[-]$ represent the reaction rate and the corresponding stoichiometric coefficient of species $i$ for the $j^{\text {th }}$ reaction; $\lambda\left[\mathrm{s}^{-1}\right]$ is the kinetic water-gas mass transfer coefficient; $H$ [-] is the dimensionless Henry's law coefficient, and $t[\mathrm{~s}]$ is the time. For transport in the aqueous phase (Eq. 7), q $[\mathrm{m} / \mathrm{s}]$ denotes the specific discharge vector and $\mathbf{D}\left[\mathrm{m}^{2} / \mathrm{s}\right]$ is the hydrodynamic dispersion tensor, which, in a 2-D coordinate system aligned in the principal flow directions, can be expressed as:

$$
\mathbf{D}=\left[\begin{array}{cc}
D_{L} & 0 \\
0 & D_{T}
\end{array}\right]
$$

To parameterize the entries of the dispersion tensor, we used the empirical expressions developed in detailed experimental and pore-scale modeling studies in granular porous media: a linear parameterization for the longitudinal component (Guedes de Carvalho and Delgado, 2005), and a non-linear, compound-specific parameterization for transverse dispersion (Chiogna et al., 2010; Hochstetler et al., 2013; Rolle et al., 2013a):

$$
D_{L}=D_{P}+0.5 d v
$$




$$
D_{T}=D_{P}+D_{a q}\left(\frac{P e^{2}}{P e+2+4 \delta^{2}}\right)^{\beta}
$$

where $D_{a q}\left[\mathrm{~m}^{2} / \mathrm{s}\right]$ is the aqueous diffusion coefficient, $D_{P}\left[\mathrm{~m}^{2} / \mathrm{s}\right]$ is the pore diffusion coefficient, $P e$ [-] (= $v d / D_{a q}$ with $v$ and $d$ being the seepage velocity and the grain size diameter, respectively) is the grain Péclet number, $\delta$ [-] denotes the ratio between the length of a pore channel to its hydraulic radius, and $\beta[-]$ is an empirical exponent that accounts for the effects of incomplete mixing in the pore channels. The values of $\delta=5.37$ and $\beta=0.5$, determined in laboratory experiments performed with different grain sizes and seepage velocities in both 2-D and fully 3-D porous media (Ye et al., 2015a), were adopted in this study.

In the transport simulations of the conservative and the reactive flow-through experiments, the gas partitioning parameters $\left(\theta_{g}\right.$ and $\left.\lambda\right)$ were considered as fitting parameters and determined based on the measured oxygen concentrations.

\subsubsection{Numerical simulations}

The batch experiments were simulated using the widely used geochemical code PHREEQC (Parkhurst and Appelo, 2013), considering a closed system and implementing the kinetically controlled pyrite oxidation reaction and the chemical framework presented above. The considered stoichiometry is described in Eq. [1-2] and the kinetics of the oxidative dissolution of pyrite by oxygen was implemented according to Eq. [4]. The outcomes from the model calculations were compared with the experimentally measured consumption of $\mathrm{O}_{2}$ and the evolution of the water chemistry parameters in the solution. In particular, these reactants and products concentrations were determined in order to obtain the best-fit specific surface area to solution volume ratio $\left(A_{e} / V_{w}\right)$ in Eq. [4] for our reactive system. The optimization procedure was performed by following the approach described in Haberer et al., (2015), which involves using the MATLAB ${ }^{\circledR}$ function lsqnonlin, and by coupling the PHREEQC reaction calculations with MATLAB ${ }^{\circledR}$ utilizing the 
303 IPhreeqcCOM module (Charlton and Parkhurst, 2011). This especially designed PHREEQC 304 module allows all the native features of PHREEQC to be effectively used in other software 305 programs or programming languages (e.g., Charlton and Parkhurst, 2011; Wissmeier and Barry, 306 2011).

307 For reactive transport in flow-through systems a convenient approach consists in coupling transport codes with PHREEQC as geochemical engine to simulate complex subsurface problems (e.g., Appelo and Rolle, 2010; Nardi et al., 2014; Prommer et al., 2003; Rolle et al., 2018). In this study we adopted, both for the 1-D and 2-D setups, a coupling procedure based on a sequential noniterative operator splitting approach utilizing the IPhreeqcCOM module (Muniruzzaman and Rolle, 2016). In such a way, the solution of the physical transport processes is carried out for a given time step and, subsequently, the calculated species/components concentrations are passed to IPhreeqc to perform the reaction calculations. We used a finite volume method to solve the 1-D and the 2-D transport problems. In the simulations of 1-D column setup, we used the Crank-Nicholson scheme for the spatial discretization and temporal integration of the transport equations. For the 2-D flowthrough chamber we used the method presented by (Cirpka et al., 1999), with an upwind differentiation scheme for the spatial discretization, the explicit Euler method for the advection (with Courant number, $\mathrm{Cr}=1$ ) and the gas partitioning problems, and the implicit Euler method for the computation of the 2-D dispersion problem. In both 1-D and 2-D simulations, the system of discretized algebraic transport equations was solved with the direct matrix solver UMFPACK (Davis and Duff, 1997) and the whole reactive transport simulator was implemented in MATLAB ${ }^{\circledR}$. Within the reaction step, all the aqueous and mineral reactions were simulated by considering a batch reactor in each cell of the simulation domain. Further details regarding the IPhreeqc coupling and the relevant solution steps can be found in Muniruzzaman and Rolle (2016). 


\section{Results and discussion}

\subsection{Batch experiments}

Two series of batch experiments, stirred at different velocities, were performed to study the kinetics of pyrite oxidation. The main water chemistry parameters that were measured to characterize the pyrite oxidation kinetics were the consumption of oxygen due to the reaction with the pyrite mineral and the total iron and sulfur concentration produced by the redox reaction.

The trends of observed $\mathrm{O}_{2}, \mathrm{Fe}$ and $\mathrm{S}$ concentrations for the two batch experiments are plotted in Fig. 2. The oxygen concentrations were determined with the non-invasive optode technique, whereas the concentrations of iron and sulfur were measured with ICP-OES and the data points in the figure represent the average of two replicates. The batch experiment stirred at $300 \mathrm{rpm}$ (Batch 1) reached anoxic conditions after $100 \mathrm{~h}$ of experiment (Fig. 2a), while the one stirred more gently (at $100 \mathrm{rpm}$, Batch 2) did not reach anoxic conditions within the total duration of the experiment (333 h, Fig 2b). In Batch 1, the concentration of Fe and $\mathrm{S}$ in solution increased due to the oxidative dissolution of pyrite and reached concentrations of $\sim 1 \times 10^{-3} \mathrm{~mol} / \mathrm{L}$ and $\sim 1.4 \times 10^{-3} \mathrm{~mol} / \mathrm{L}$ for Fe and $\mathrm{S}$ respectively, once the oxygen was entirely consumed. Fe and $\mathrm{S}$ in Batch 2 also increased accordingly with the partial depletion of $\mathrm{O}_{2}$ (from $2.6 \times 10^{-4} \mathrm{~mol} / \mathrm{L}$ to $1.5 \times 10^{-4} \mathrm{~mol} / \mathrm{L}$ ), reaching values of $4.5 \times 10^{-4} \mathrm{~mol} / \mathrm{L}$ for $\mathrm{Fe}$ and $6.7 \times 10^{-4} \mathrm{~mol} / \mathrm{L}$ for $\mathrm{S}$ at the end of the experiment.

The batch experiments were modeled considering a volume of $20 \mathrm{~mL}$ of aerobic solution, $1 \mathrm{~g}$ of pyrite and a gas phase volume of $6.8 \mathrm{~mL}$, representing the headspace in the bottles and having an oxygen partial pressure of $0.21 \mathrm{~atm}$. The volume of the aqueous and gas phases was not changed throughout the simulations. The fitting parameter for the pyrite oxidation kinetic, $A_{e} / V_{w}$, was adjusted in order to simultaneously fit the experimentally measured reactant $\left(\mathrm{O}_{2}\right)$ and products $(\mathrm{Fe}$ and S). As best-fit results, we obtained values of $A_{e} / V_{w}$ equal to $47 \mathrm{~m}^{2} / \mathrm{mol} / \mathrm{L}_{\mathrm{w}}$ and $3.3 \mathrm{~m}^{2} / \mathrm{mol} / \mathrm{L}_{\mathrm{w}}$ for Batch 1 and Batch 2, respectively. The reduction in stirring velocity caused a significant 
350

351 overestimated compared to the measured values.

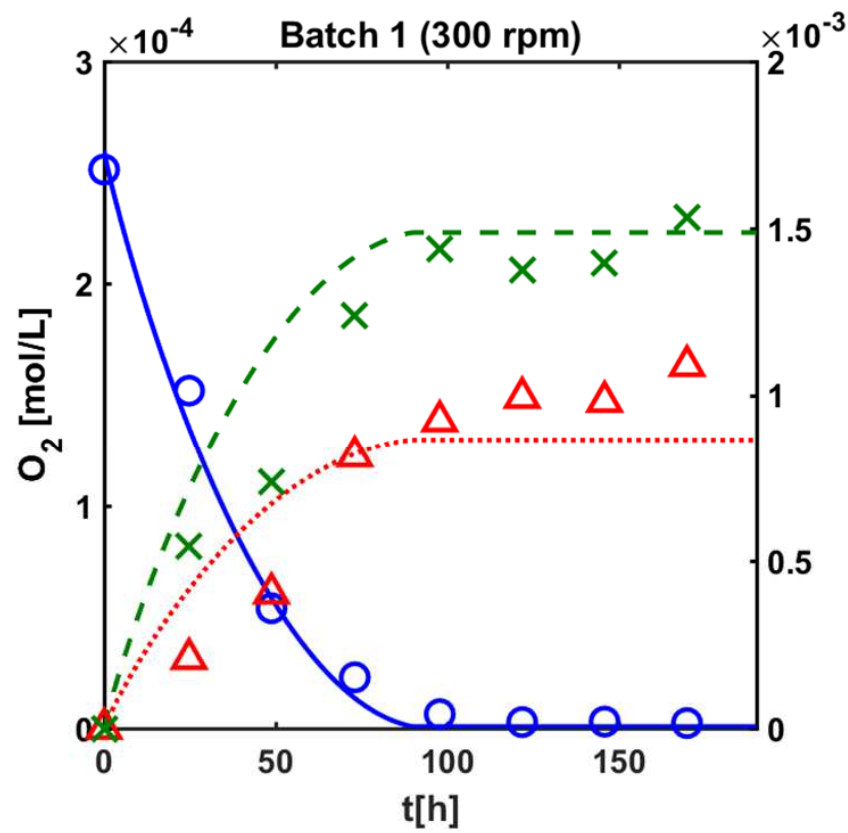

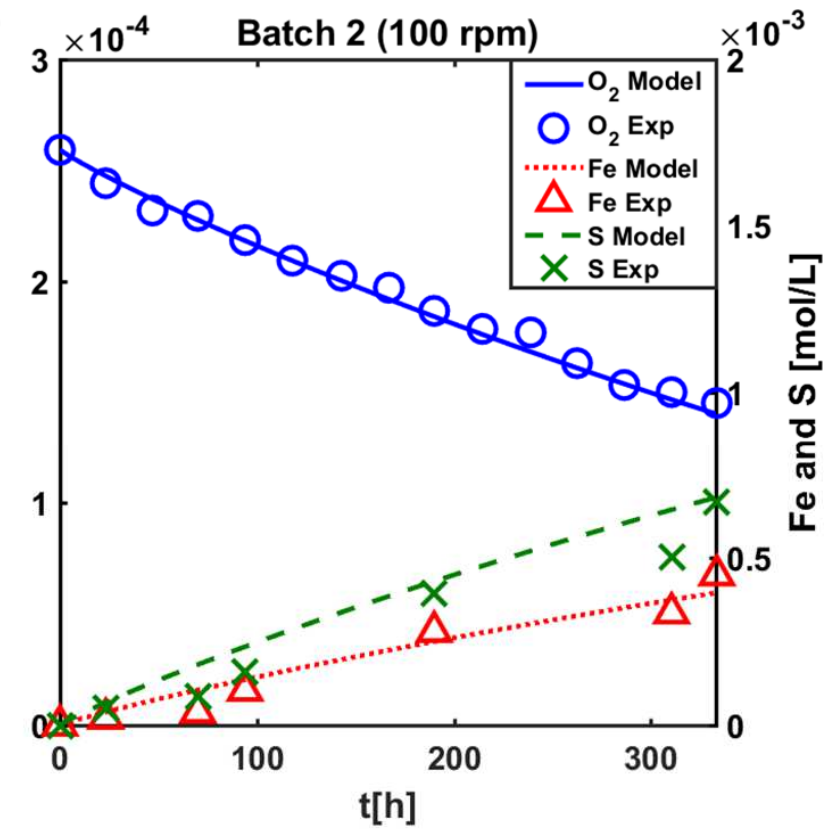

th]
355

decrease in the reaction rate (Eq. [2]), by reducing the effectiveness of the contact between the solution and the reactive surface of the mineral. The model reproduced the experimental data obtained in both Batch 1 and Batch 2. The oxygen consumption and the production of iron are captured very well, whereas the simulated sulfur concentrations appeared to be slightly

Fig. 2. Observed (symbols) and simulated (lines) concentrations of reactants and products in the two series of batch experiments performed with different agitation.

\subsection{Column experiments}

1-D column experiments with no pyrite inclusions were performed to track the propagation of nonreactive oxygen fronts in porous media under flow-through conditions. The experiments lasted 15 hours and the $\mathrm{O}_{2}$ concentration were measured inside the porous medium with two fiber optic cables located at $7.5 \mathrm{~cm}$ and close to the outlet of the column $(12.5 \mathrm{~cm})$. Measurements of oxygen breakthrough were recorded at high temporal resolution (5 $\mathrm{min})$. 
The experimental results show a characteristic mass-transfer limited behavior of oxygen in the column, resulting in the retardation and tailing of the breakthrough curves. A conservative transport model, including kinetic partitioning of oxygen between the pore water and a residual trapped gas phase, allowed us to capture the observed breakthrough behavior (Fig. 3). The parameters $\theta_{g}$ and $\lambda$ in Eq. [8] were obtained by fitting the experimental data. We obtained values of 0.0163 for the volumetric gas content and $1.27 \times 10^{-5} \mathrm{~s}^{-1}$ for the mass transfer coefficient. Although the volume of the entrapped gas phase is minimal, it considerably impacts the propagation of the oxygen front, as also reported in a previous study (Donaldson et al., 1997). The extent of retardation and tailing of

372 the oxygen breakthrough curves becomes evident when the trends are compared to the breakthrough 373 of a non-partitioning dissolved tracer. The simulations of the tracer behavior show curves that are 374 considerably steeper and less spread compared to the observed behavior of oxygen. For instance, 375 the oxygen breakthrough at $x=12.5 \mathrm{~cm}$ shows that the concentrations reach steady state after $10 \mathrm{~h}$, 376 whereas the prediction for the non-partitioning tracer at the same location indicates that steady-state 377 conditions are already reached after approximately $2 \mathrm{~h}$. 


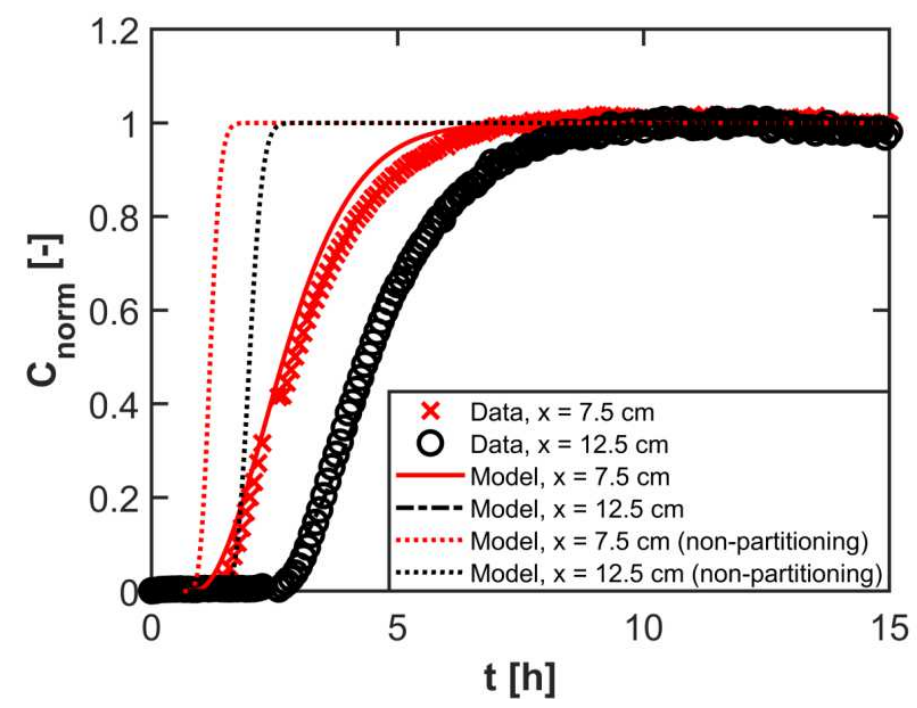

379 Fig. 3. Observed (symbols) and simulated (lines) breakthrough curves of $\mathrm{O}_{2}$ in the conservative 380 column experiment at two different locations: $x=7.5 \mathrm{~cm}$ and $x=12.5 \mathrm{~cm}$. The dotted lines represent 381 the simulated $\mathrm{O}_{2}$ breakthrough with no gas partitioning.

382 Reactive column experiments were performed to investigate the propagation of $\mathrm{O}_{2}$ fronts in porous 383 media in the presence of pyrite. Fig. 4 shows the high-resolution measurements of oxygen 384 concentrations obtained with the optode sensor technique. The spatial profiles were taken at 385 different times for all three columns, in which different inclusions of reactive pyrite were 386 embedded. 
(a) Column 1

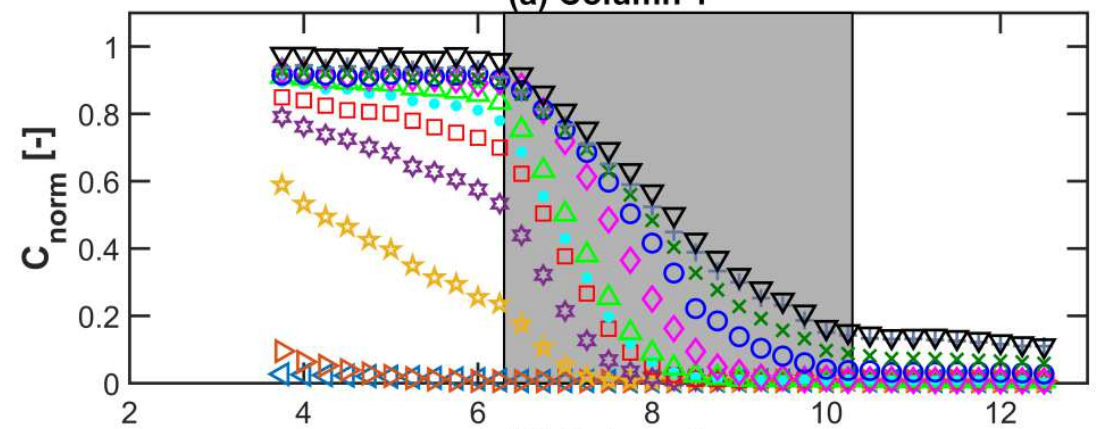

(b) Column 2

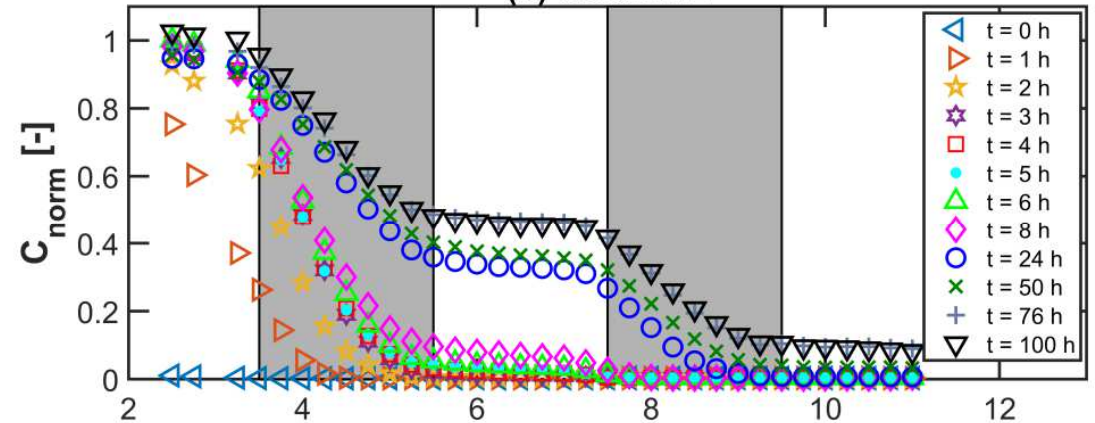

(c) Column 3

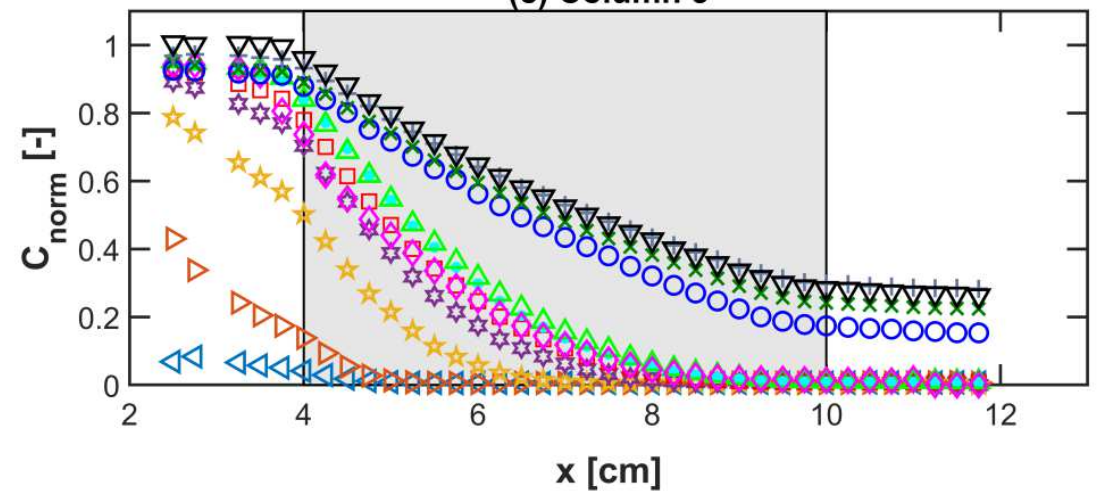

Fig. 4. Spatial profiles of oxygen concentrations measured during the reactive experiments in the three chemically heterogeneous column setups (the grey areas show the reactive pyrite inclusions; the different colors of the inclusions represent their different concentration, dark gray: pure pyrite inclusion, light gray: pyrite mixed with sand).

The measurements show the evolution of the reactive systems with initial anoxic conditions that are progressively impacted by the injection of oxic water at the columns' inlets and the reaction with the pyrite mineral. The effect of the geochemical heterogeneity clearly affects the transport of oxygen: as soon as the $\mathrm{O}_{2}$ fronts reach the reactive mineral inclusions, oxygen is depleted due to the oxidative dissolution of pyrite (Eq. 1). At late time, the systems approach steady-state conditions 
with respect to the oxygen spatial profiles that become stable. This behavior results from the dynamic balance between the oxygen supplied from the inlet and its consumption due to the reaction with pyrite within the porous media. Column 1 shows a remarkable decrease of oxygen throughout the length of the reactive inclusion and steady-state $\mathrm{O}_{2}$ concentration values at the outlet are approximately $15 \%$ compared to the inlet. The measurements of oxygen in Column 2 show patterns that are initially impacted only by the first pyrite inclusion, which effectively consumes the injected oxygen. Successively, the oxygen front reaches the second inclusion (at $t=8 \mathrm{~h})$ and a pattern with stepwise consumption of oxygen in the two reactive zones develops. Since the concentration of $\mathrm{O}_{2}$ reaching the first inclusion is higher than the $\mathrm{O}_{2}$ reaching the second inclusion, the reaction rate is faster in the first zone of geochemical heterogeneity compared to the reactive zone downgradient (the average reaction rates for the first and the second inclusions are $4.30 \times 10^{-8}$ $\mathrm{mol} / \mathrm{L} / \mathrm{s}$ and $1.99 \times 10^{-8} \mathrm{~mol} / \mathrm{L} / \mathrm{s}$, respectively). This results in an oxygen concentration slope inside the first inclusion that is steeper than in the second inclusion and in a higher $\mathrm{O}_{2}$ consumption within the first reactive zone. Similarly to Column 1, also in Column 2 the steady-state concentration of oxygen at the outlet of the columns reaches approximately $15 \%$ of the inlet. The trend observed in Column 3 is similar to the one observed in Column 1 with the decrease of oxygen in the reactive inclusion. However, the observed slopes are now less steep since the reactive mineral concentration in this setup was smaller compared to Column 1 and Column $2\left(12.85 \mathrm{~mol} / \mathrm{L}_{\text {bulk }}\right.$ in Column 3 and $25.7 \mathrm{~mol} / \mathrm{L}_{\text {bulk }}$ in Column 1 and Column 2). Consequently, slower consumption rates and a higher steady-state concentration of oxygen are observed at the outlet of Column 3 (approx. 27\% of the inlet value). The average reaction rates calculated for the $1 \mathrm{D}$-flow through experiments, and the consequent oxygen consumption, depends on the initial concentration of the pyrite inclusions: in Column 1 and 2 the average reaction rates are very close to each other, $3.13 \times 10^{-8} \mathrm{~mol} / \mathrm{L} / \mathrm{s}$ and 3.12 $\times 10^{-8} \mathrm{~mol} / \mathrm{L} / \mathrm{s}$ (for Column 1 and the average of the two inclusions in Column 2, respectively) while 
422 in Column 3 the average reaction rate is $1.88 \times 10^{-8} \mathrm{~mol} / \mathrm{L} / \mathrm{s}$. The reactive transport experiments 423 were simulated with the modeling approach described in Section 2.2. Table 1 summarizes the 424 parameters of the reactive transport simulations for both the 1-D column experiments and for the 2425 D flow-through chamber. The kinetics of pyrite oxidative dissolution was simulated as in the batch 426 setups by using the rate expression of Eq. 4 . The best-fit value of the kinetic parameter $A_{e} / V_{w}$ was $4272.8 \mathrm{~m}^{2} / \mathrm{mol} / \mathrm{L}_{\mathrm{w}}$, which was closer to the gently stirred batch system (Batch 2 ). The obtained result is 428 also consistent with the geometrically calculated value (for $A_{e}$ ) of $0.717 \mathrm{~m}^{2} / \mathrm{mol}$ (i.e., assuming 429 spherical grains with $d=200 \mu \mathrm{m}$ and $\rho_{s, p y r i t e}=5.02 \mathrm{~kg} / \mathrm{L}$ ) and the value of $5.64 \mathrm{~m}^{2} / \mathrm{mol} \mathrm{reported} \mathrm{by}$ 430 Williamson and Rimstidt (1994). The same value was also used to simulate the 2-D flow-through 431 experiment. We accounted for the precipitation of an iron (hydr)oxide phase (FeOOH) considering 432 a stability of the mineral intermediate between ferrihydrite and goethite $(\log \mathrm{K}=2.50) . \mathrm{FeOOH}$ 433 precipitation was described according to the stoichiometric reaction described in Eq. [3] and the 434 effective rate constant was calculated according to Eq. [6].

Table 2. Geometry of the flow-through domains and parameters used in the reactive transport 436 simulations.

\begin{tabular}{lcc}
\hline \multicolumn{1}{c}{ Parameter } & 1-D columns & 2-D setup \\
\hline Domain size $(L \times W)[\mathrm{cm}]$ & 14.5 & $80 \times 24$ \\
Discretization $(\Delta x \times \Delta z)[\mathrm{cm}]$ & 0.1 & $1 \times 0.1$ \\
Time step, $\Delta t[\mathrm{~s}]$ & 58 & 576 \\
Oxygen diffusion coefficient $\left[\mathrm{m}^{2} / \mathrm{s}\right]$ & $2 \times 10^{-9}$ & $2 \times 10^{-9}$ \\
Porosity [-] & 0.38 & 0.38 \\
Volumetric water content, $\theta_{w}[-]$ & 0.347 & 0.358 \\
Volumetric gas content, $\theta_{g}[-]$ & 0.033 & 0.022 \\
Kinetic water-gas mass transfer coefficient, $\lambda\left[\mathrm{s}^{-1}\right]$ & $1.95 \times 10^{-6}$ & $4.26 \times 10^{-6}$ \\
Henry's coefficient for oxygen, $H[-]$ & 31.25 & 31.25 \\
Reactive specific surface area, $A_{e} / V_{w}\left[\mathrm{~m}^{2} / \mathrm{mol} / \mathrm{L}_{\mathrm{w}}\right]$ & 2.8 & 2.8 \\
FeOOH effective rate constant, $k_{e f f}[\mathrm{~mol} / \mathrm{L} / \mathrm{s}]$ & $5 \times 10^{-15}$ & $1.5 \times 10^{-13}$ \\
\hline
\end{tabular}

437 The comparison between the measured oxygen concentrations and the outcomes of the reactive transport simulations is shown in Fig. 5 for selected spatial profiles in the different column setups. 
439 The agreement between observed and simulated oxygen concentrations is very good, particularly 440 after some time from the beginning of the flushing in the reactive columns. The model can 441 reproduce both the shape of the profile and the magnitude of the oxygen concentrations measured 442 within the chemically heterogeneous porous media. A small discrepancy between the model and the 443 measured data is seen mainly in the profiles simulated at early time (after 4 hours of experiment), 444 which show a simulated reactive $\mathrm{O}_{2}$ front propagating faster than the experimental observation. This 445 is probably due to the assumption of homogeneous distribution of the entrapped gas phase made in 446 the model, whereas in the experiments the gas bubbles are more likely heterogeneously distributed 447 within the porous media and their impact is more significant at early time.
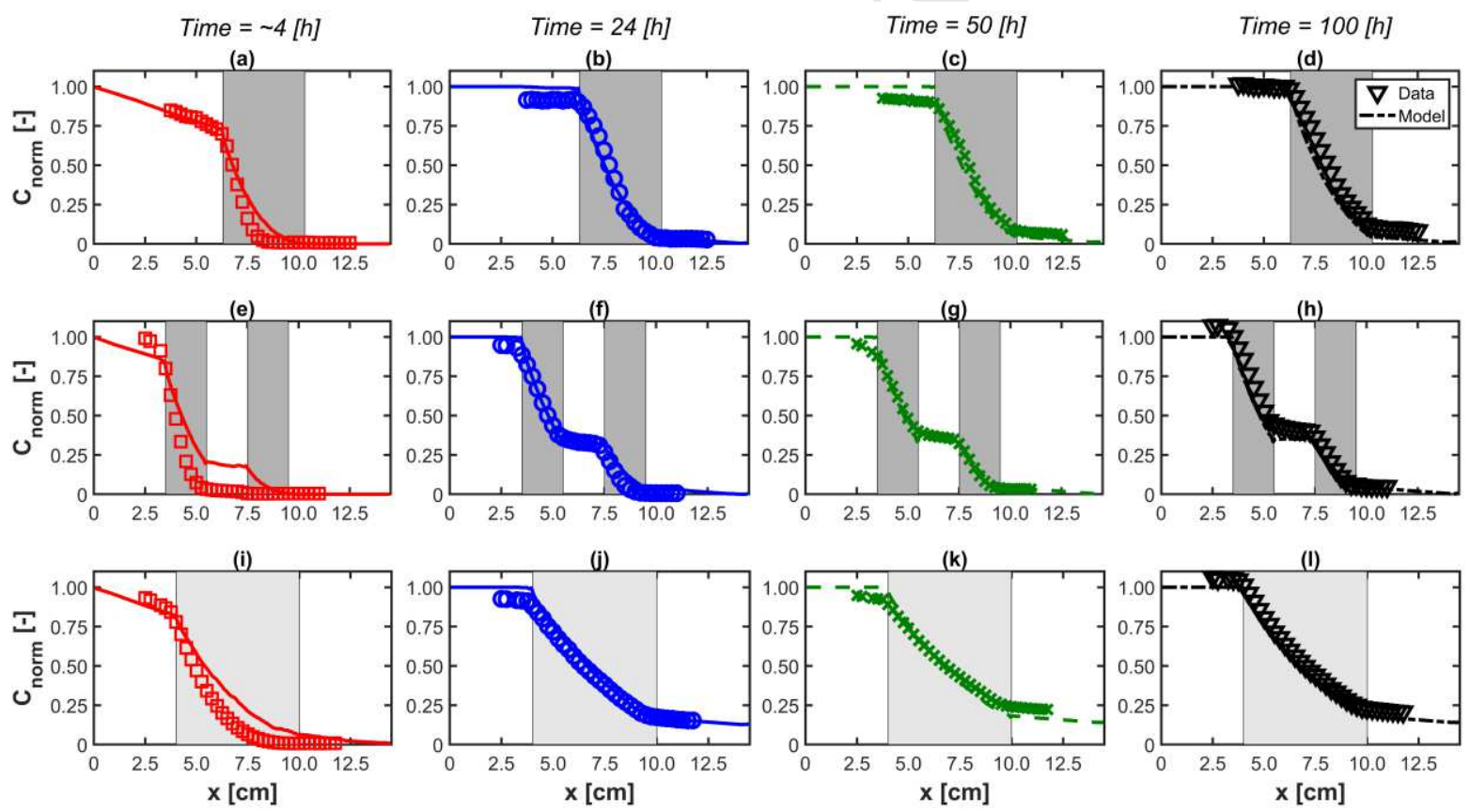

Fig. 5. Comparison between observed (symbols) and simulated (lines) $\mathrm{O}_{2}$ spatial profiles in Column $451 \quad 1(a-d)$, Column $2(e-h)$ and Column $3(i-l)$ at different time steps. The gray areas show the location of the reactive pyrite inclusions; the different colors of the inclusions represent their different concentration, dark gray: pure pyrite inclusion, light gray: pyrite mixed with sand. 
454 The breakthrough of iron and sulfur were measured at the outlet of the column setups. The concentrations of $\mathrm{Fe}$ and $\mathrm{S}$ remained close to the background content during the first 5 hours of experiment and then increased until a steady-state value, which was reached after almost 24 hours. The steady-state concentrations measured in the effluent of Columns 1 and 2 were close to $0.5 \times 10^{-4}$ $\mathrm{mol} / \mathrm{L}$ for Fe and $1.3 \times 10^{-4} \mathrm{~mol} / \mathrm{L}$ for $\mathrm{S}$, while in Column 3 they were slightly lower: $0.4 \times 10^{-4} \mathrm{~mol} / \mathrm{L}$ for Fe and $1.1 \times 10^{-4} \mathrm{~mol} / \mathrm{L}$ for $\mathrm{S}$ (Fig. 6). $\mathrm{pH}$ was measured at the outlet of the columns at the end of the experiments and ranged between 4.5 and 4.9, showing a decrease from the initial value of 5.8 due to the release of protons from the oxidation of pyrite, Eq. [1]. Similarly, in Column 1 and 2, the reactive $\mathrm{O}_{2}$ steady-state concentration was fluctuating between $0.2 \times 10^{-4} \mathrm{~mol} / \mathrm{L}$ and $0.3 \times 10^{-4} \mathrm{~mol} / \mathrm{L}$, lower than the concentration reached at steady state in Column 3 , around $0.7 \times 10^{-4} \mathrm{~mol} / \mathrm{L}$. The stoichiometric ratio of the reaction products highlights the precipitation of a small amount of $\mathrm{Fe}$ as a secondary phase mineral in the porous media. This is supported by the observation of a $\mathrm{S} / \mathrm{Fe}$ ratio at the outlet (2.2-2.5) that is higher than the stoichiometric ratio of the mineral used in the reactive inclusions (1.72). The reactive transport simulations with the parameter values reported in the second column of Table 2 allowed us to reproduce well also the trend of iron and sulfur observed in the different experiments. The breakthrough curves of these dissolved species, produced during pyrite oxidative dissolution, also show a tailing behavior that depends on the kinetic partitioning and retardation of the oxygen front.

In the reactive experiments oxygen breakthrough was also continuously measured close to the outlet $(x=11.75 \mathrm{~cm})$ of the columns. The comparison between the $\mathrm{O}_{2}$ concentration in the conservative and reactive column experiments (circles and squares, respectively) is reported in Fig 6d-f. The difference in oxygen breakthrough allows visualizing the effect of the pyrite reactivity in the oxygen consumption, resulting in $\mathrm{O}_{2}$ steady-state concentrations considerably lower in the reactive rather than in the conservative experiments. The simulated breakthrough of oxygen is also reported 
478 in Fig. 6d-f for both the conservative and the reactive cases. It is possible to calculate the mass of 479 oxygen consumed by the reaction with pyrite in the different setups with the following mass 480 balance:

$$
M_{O_{2}}=\int_{0}^{T}\left(\dot{m}_{O_{2}, \text { cons }}-\dot{m}_{O_{2}, \text { react }}\right) d t
$$

481 where $M_{O 2}[\mathrm{~g}]$ is the mass of oxygen consumed and $\dot{\mathrm{m}}_{\mathrm{O} 2 \text {,cons }}$ and $\dot{\mathrm{m}}_{\mathrm{O} 2 \text {,react }}[\mathrm{g} / \mathrm{s}]$ are the mass fluxes of oxygen in the conservative and reactive experiments, respectively. The mass balance was calculated considering the outcomes of the simulations and a duration of all experiments of $100 \mathrm{~h}$. The results show a similar mass of oxygen consumed in Column 1 and Columns 2 (4.01 mg and $4.03 \mathrm{mg}$ ), whereas the results for Column 3 show a smaller oxygen depletion (3.49 mg).
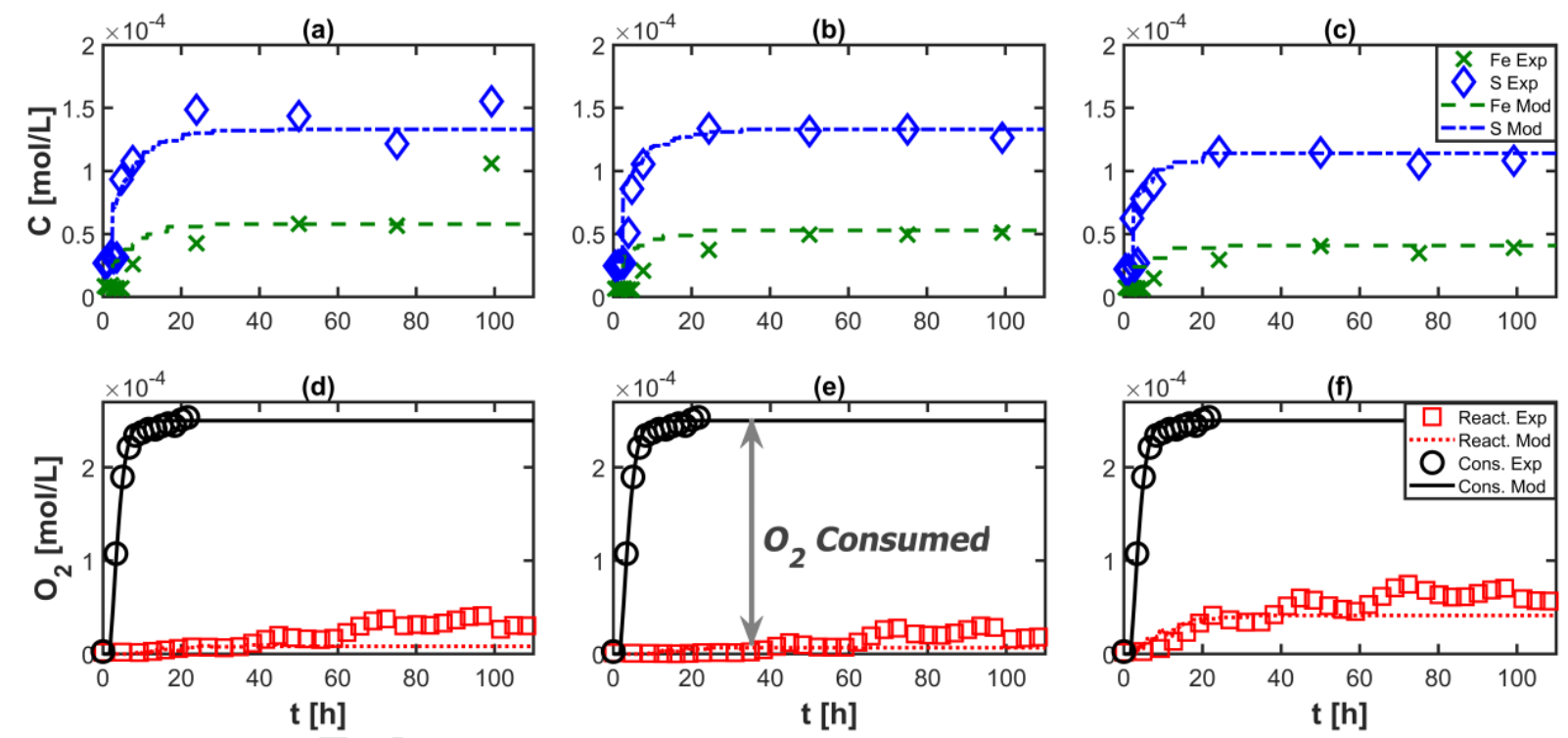

Fig. 6. Observed (symbols) and simulated (lines) breakthrough curves of $\mathrm{Fe}, \mathrm{S}(\mathrm{a}-\mathrm{c})$ and $\mathrm{O}_{2}(\mathrm{~d}$-f) for the column experiments: Column $1(a, d)$, Column 2 (b,e), and Column 3 (c,f). Fe and S breakthrough curves were measured at the outlet of the column, whereas the oxygen breakthrough was measured at $x=11.75 \mathrm{~cm}$. 
491

492

493

494

495

496

497

\subsection{2-D Flow-through experiments}

In the 2-D flow-through chamber a rectangular inclusion of pyrite $(16 \mathrm{~cm} \times 4 \mathrm{~cm}$ with a concentration of $12.85 \mathrm{~mol} / \mathrm{L}_{\text {bulk }}$ ) was embedded within the sandy porous matrix. The system was initially maintained under anoxic conditions and, at the beginning of the experiment, an inflowing oxic solution was injected into the chamber at the seepage velocity of $1.5 \mathrm{~m} /$ day. Vertical $\mathrm{O}_{2}$ concentration profiles were measured at $16 \mathrm{~cm}, 32 \mathrm{~cm}, 48 \mathrm{~cm}$ and $64 \mathrm{~cm}$ from the inlet at different time intervals during the experiment. A visual illustration of the 2-D experiments is provided in Fig. 1 and the outcomes of the reactive transport simulations for that setup are reported in Fig. 7. The maps of Fig. 7 represent the results of the model at steady-state conditions with respect to oxygen and show: (a) the consumption of dissolved oxygen upon its contact with the pyrite and the formation of an oxygen-depleted plume in the center of the flow-through chamber, (b) the small consumption of the reactive pyrite mineral that was present in large stoichiometric excess, and (c) the precipitation of the $\mathrm{FeOOH}$ phase upon the contact of dissolved iron from the oxidation of pyrite with oxygen in the inclusion and at the lateral fringes, where the reactants can mix by transverse hydrodynamic dispersion. The 2-D simulations were performed with the approach based on coupling the two-dimensional transport code and IPhreeqc to solve the geochemical reaction network (section 2.2). The values of the kinetic and transport parameters used in the simulation are listed in the third column of Table 2. 

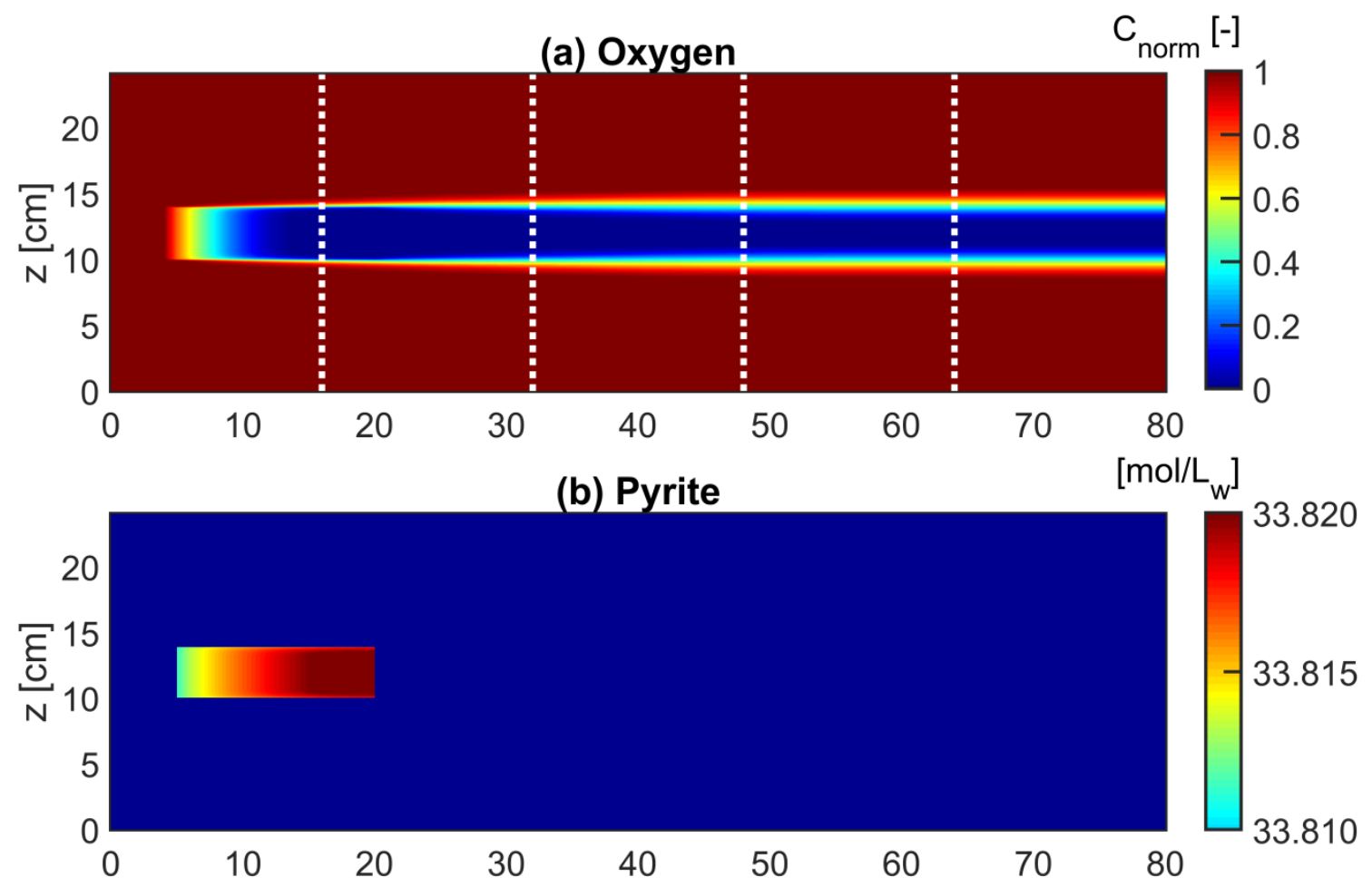

(c) $\mathrm{FeOOH}$

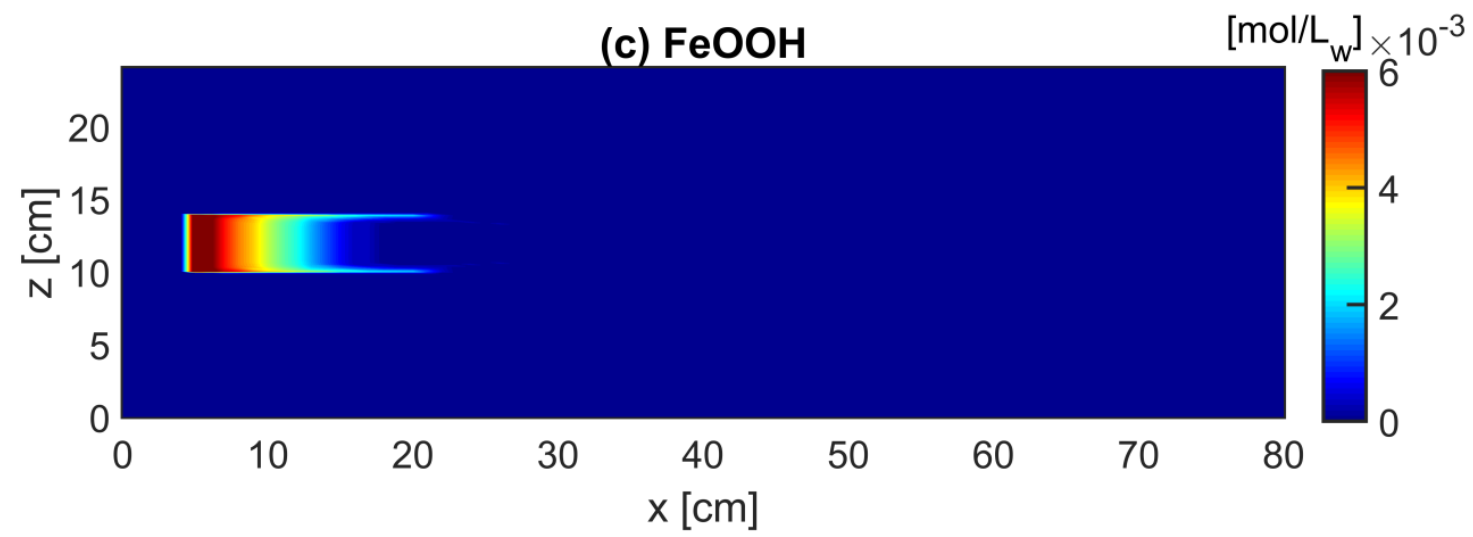

509

510 Fig. 7. Simulated spatial distributions of (a) $\mathrm{O}_{2}$ concentration (b), pyrite content (b), and (c) 511 FeOOH precipitate in the 2-D flow-through chamber after 98 hours.

512 The spatially distributed measurements of oxygen concentrations at the four sensor strips allowed 513 us to follow the dynamics of oxygen transport and consumption in the 2-D flow-through system. 514 Fig. 8 shows measurements at different times from the beginning of the experiments and the 515 comparison with the reactive transport simulation of the 2-D setup. The oxygen front advances in 
516 the 2-D flow-through chamber and the consumption upon reaction with the embedded reactive 517 pyrite is first recorded at the location of the first sensor strip $(x=16 \mathrm{~cm})$. The signature of oxygen 518 depletion due to the reaction with pyrite becomes successively visible at the downgradient sensor 519 measurement cross sections as the oxygen front moves through the domain. At late times the 520 oxygen vertical profiles stabilize and approach steady-state conditions with a clear indication of an 521 oxygen depleted plume in the central zone of the flow-through chamber. The reactive transport 522 model captured the spatial and temporal dynamics of oxygen transport and consumption in the 2-D 523 flow-through setup. The model reproduces well both the shapes and the spatially-distributed oxygen 524 values measured during the flow-through experiments. The good agreement between measured and 525 simulated oxygen concentrations show the capability of the model to reproduce the experimental 526 data including the steep lateral gradients observed in the flow-through experiment. Similarly to the 527 column experiments, the discrepancy between measurements and simulations is more pronounced at 528 early times and the agreement progressively improves in the course of the experiment as the 529 oxygen-depleted plume approaches steady state. 

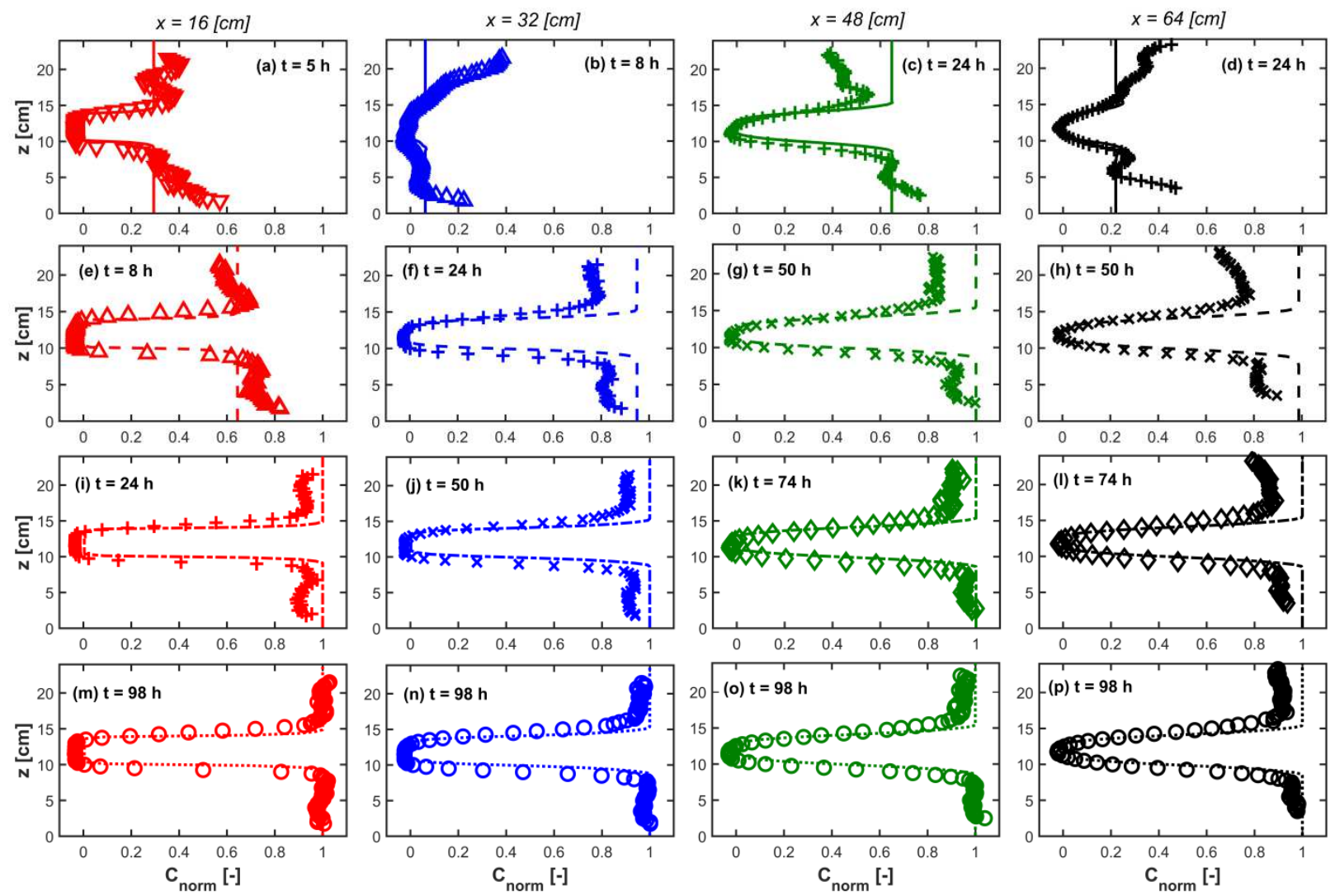

530

Fig. 8. Experimental (symbols) and simulated (lines) $\mathrm{O}_{2}$ concentration profiles at the four sensors strips locations $(x=16,32,48$, and $64 \mathrm{~cm})$ in the 2-D flow-through chamber at different times.

Iron, sulfur and $\mathrm{pH}$ were measured at the outlet of the flow-through chamber after 98 hours of experiment. In Fig. 9 the values of these dissolved species measured at each port $(1.2 \mathrm{~cm} \mathrm{spacing})$ at the outlet of the chamber are plotted together with the results of the reactive transport simulations. The Fe concentration at the outlet of the chamber is close to zero since all the iron dissolved from the pyrite oxidation was precipitated as iron (hydr)oxides upon contact with dissolved oxygen through transverse mixing (Fig. 9a). Sulfur, instead, shows a distinct plume with the peak concentration aligned with the reactive mineral inclusion and with a width of approximately $7 \mathrm{~cm}$. This behavior results from the oxidative dissolution of the pyrite, the downgradient advective transport, and the lateral dispersion and mixing of the dissolved products with the background solution. The reactive transport model, incorporating the measured stoichiometry of the mineral and 
543 the kinetic and transport parameters described above and summarized in Table 2, successfully 544 reproduces the experimental steady-state aqueous concentrations of sulfur and iron measured at the 545 outlet of the flow-through chamber. The model appears to predict lower $\mathrm{pH}$ values compared to the 546 measured ones. This discrepancy can be ascribed to the fact that the current version of the model does not include the complex surface/solution interaction of protons in silica porous media (e.g., McNeece and Hesse, 2017, 2016). The sorption of protons could explain the experimental observations in which this process appears to buffer the acidification due to pyrite oxidation and the difference compared to the reactive transport simulations in which these surface/solution interactions were not included.
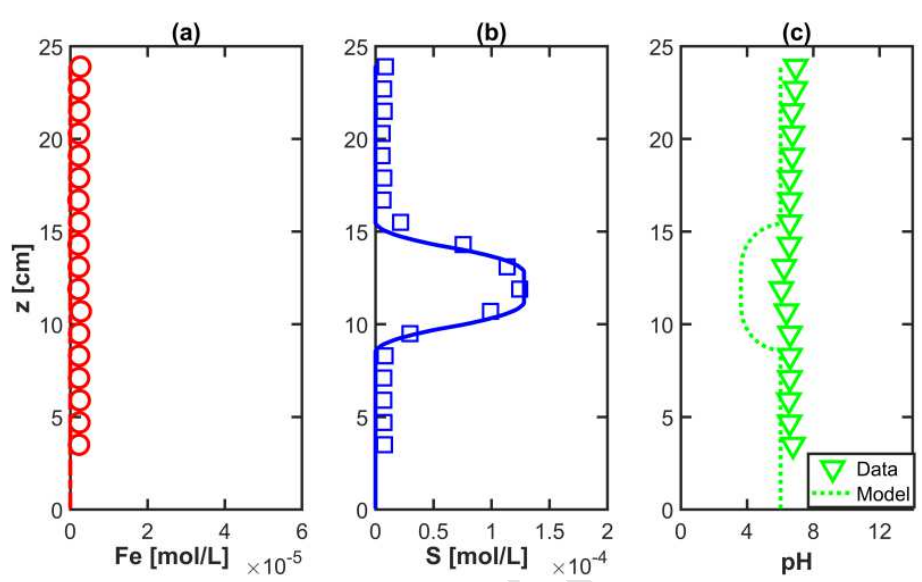

553 Fig. 9. Measured (symbols) and simulated (lines) vertical profiles of $F e(a), S(b), p H(c)$ at the 554 outlet of the 2-D flow-through chamber after $t=98$ hours.

Breakthrough curves of oxygen at the outlet of the flow-through chamber were measured to characterize the transient transport of oxygen in the 2-D setup. Measurements were taken at two distinct locations along the most downgradient sensor strip $(x=64 \mathrm{~cm})$ : outside of the $\mathrm{O}_{2}$ plume, above the pyrite inclusion, and inside the oxygen-depleted plume where oxygen was significantly consumed (Fig. 10). As in the column setups, also in the 2-D flow-through experiment the oxygen breakthrough curves were affected by a retardation effect due to the small gas bubbles entrapped in the porous medium. The comparison between the two curves highlights the effect of pyrite 
reactivity on the consumption of oxygen. The reactive transport simulations shown in Figs. 7-10 were performed with $\theta_{g}=0.022$ and $\lambda=4.26 \times 10^{-6} \mathrm{~s}^{-1}$, values that are similar to the ones obtained for the 1-D column setups.

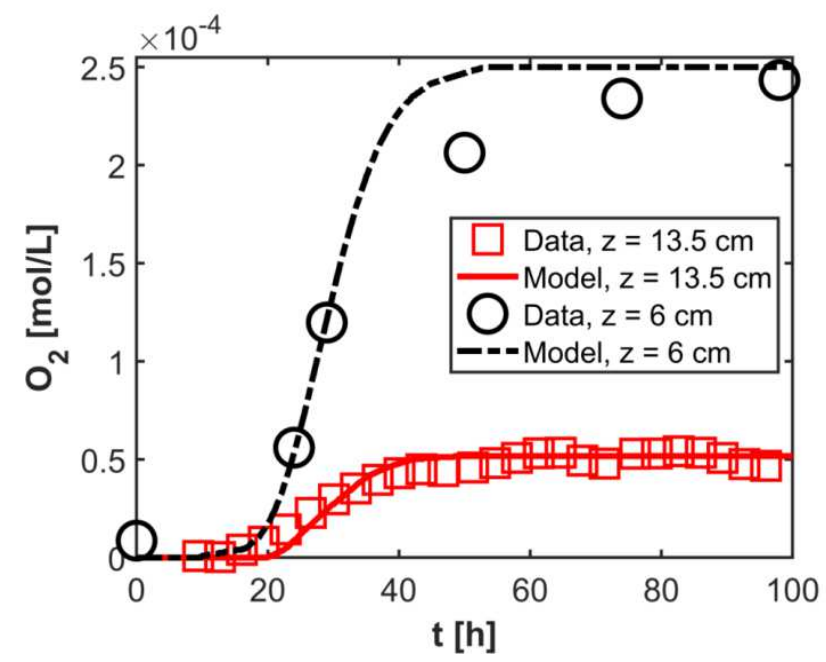

Fig. 10. Oxygen breakthrough curves measured on the last oxygen sensor strip $(x=64 \mathrm{~cm})$ in the 2$D$ flow-through chamber. The squares and the solid line represent measurements and simulation at the height of the pyrite inclusion, whereas the circles and the dashed line are the observation and simulation outside the inclusion.

\section{Conclusions}

In this study, we investigated the impact of geochemical heterogeneities on the propagation of reactive fronts in porous media. We focused on pyrite oxidation that was studied in multidimensional systems. Experiments were performed in different laboratory setups including batch, 1-D columns, and a 2-D flow-through chamber.

The results of the bacth experiments allowed us to characterize the kinetics of pyrite oxidative dissolution and to formulate and test a reaction module that was, successively, used to interpret the flow-through experiments. An approach based on spatially distibuted sensor measurements was proposed to monitor oxygen transport and consumption upon reaction with pyrite in the flowthrough setups. The outcomes of the flow-through experiments demonstrate the capability of the 
proposed approach to capture the dynamics of oxygen reactive transport in porous media at high spatial and temporal resolution. The column experiments showed that both the distribution and concentration of the reactive mineral play a key role in the oxygen consumption, as indicated by the high-resolution spatial profiles measured within the porous media. Distributed spatial monitoring of oxygen concentrations, coupled with sampling and analysis of water chemistry parameters at a dense network of outlet ports, allowed us to investigate pyrite oxidation and its impact on the propagation of dissolved oxygen fronts also in the 2-D flow-through setup. In this system the results clearly show that the presence of a reactive pyrite inclusion generates an oxygen-depleted plume whose signature propagates downgradient due to the inherently poor mixing capability of subsurface porous media and, in particular, the limited extent of transverse mixing (Rolle et al., 2013b). The comparison of the experimental results in the 1-D and 2-D systems is also illustrative of the impact of dimensionality on reactive transport in porous media. In fact, although the systems in Column 3 and in the 2-D flow-through chamber were physically and chemically equivalent, the outcomes of the experiments show different results not only in the observed consumption and breakthrough of oxygen but also in the formation, transport and breakthrough of other products of pyrite oxidation. For instance, whereas the breakthrough of iron was clearly observed at the outlet of all column setups, mixing with the surrounding oxic water caused the precipitation of an iron (hydr)oxide phase and no breakthrough of iron could be observed at the outlet of the 2-D flowthrough chamber. The effects of dimensionality are likely to be even more evident by considering reactive transport in fully 3-D setups in which the topology of flow, different mixing mechanisms and different mixing enhancement compared to 2-D cases (e.g., Chiogna et al., 2015; Ye et al., 2015b, 2015c) could considerably affect the reaction extents and the impact of chemical heterogeneity on water quality. 
603 The reactive transport modeling presented in this study was instrumental for the quantitative 604 interpretation of the propagation of the oxygen fronts in the different setups. The developed 1-D and 605 2-D models coupling the main physical transport processes and the chemical reactions allowed us to 606 reproduce the spatial profiles and breakthrough curves of oxygen and the measurements of the other water chemistry parameters in the different experimental setups. In particular, the description of kinetic partitioning of oxygen with a small volume of entrapped gas phase within the porous medium was important to accurately describe the oxygen transport and retardation observed under conservative and reactive conditions in both the 1-D and 2-D setups.

This study represents one of the few experimental contributions focusing on the investigation of the effects of chemical heterogeneity in porous media and on the coupling between transport processes in multidimensional flow-through systems and geochemical reactions. We envision further work investigating the impact of spatially distributed chemical heterogeneity on the release of toxic metals and metalloids in flow-through porous media, as well as studies exploring the combined effect of physical (Muniruzzaman et al., 2014; Rolle et al., 2009) and chemical heterogeneity (Fakhreddine et al., 2016; Li et al., 2014; Salehikhoo and Li, 2015) on solute transport in subsurface porous media.

\section{Acknowledgments}

This study was funded by the Villum Block Fellowship (Villum Fonden, Denmark). M.R. also acknowledges the support of the Independent Research Fund Denmark (GIGA project). J.L. was supported by NSF EPSCOR 'Ike Wai Project OIA \#1557349. The authors would like to thank Dr. Sarah Fakhreddine (Stanford University) for the XRF and EXFAS analyses of the minerals.

647 The mineral characterization as well as experimental data for of this study are provided in the supplementary material (Fig. S1 and Tables S1-S6). 
650

651

652

653

654

655

656

657

658

659

660

661

662

663

664

665

666

667

668

669

670

671

672

673

674

675

676

677

678

679

680

681

682

683

684

685

References

Andersen, M.S., Larsen, F., Postma, D., 2001. Pyrite oxidation in unsaturated aquifer sediments. Reaction stoichiometry and rate of oxidation. Environ. Sci. Technol. 35, 4074-4079. https://doi.org/10.1021/es0105919

Appelo, C.A.J., Postma, D., 2005. Geochemistry, groundwater and pollution, 2nd ed. CRC Press/Balkema.

Appelo, C.A.J., Rolle, M., 2010. PHT3D: A Reactive Multicomponent Transport Model for Saturated Porous Media. Ground Water 48, 627-632. https://doi.org/10.1111/j.1745-6584.2010.00732.x

Battistel, M., Hurwitz, S., Evans, W.C., Barbieri, M., 2016. The chemistry and isotopic composition of waters in the low-enthalpy geothermal system of Cimino-Vico Volcanic District, Italy. J. Volcanol. Geotherm. Res. 328, 222-229. https://doi.org/10.1016/J.JVOLGEORES.2016.11.005

Bauer, R.D., Rolle, M., Bauer, S., Eberhardt, C., Grathwohl, P., Kolditz, O., Meckenstock, R.U., Griebler, C., 2009. Enhanced biodegradation by hydraulic heterogeneities in petroleum hydrocarbon plumes. J. Contam. Hydrol. 105, 56-68. https://doi.org/10.1016/J.JCONHYD.2008.11.004

Blowes, D.W., Ptacek, C.J., Jambor, J.L., Weisener, C.G., 2003. The Geochemistry of Acid Mine Drainage, in: Treatise on Geochemistry. Elsevier, pp. 149-204. https://doi.org/10.1016/B0-08-043751-6/09137-4

Charlton, S.R., Parkhurst, D.L., 2011. Modules based on the geochemical model PHREEQC for use in scripting and programming languages. Comput. Geosci. 37, 1653-1663. https://doi.org/10.1016/j.cageo.2011.02.005

Chiogna, G., Cirpka, O.A., Rolle, M., Bellin, A., 2015. Helical flow in three-dimensional nonstationary anisotropic heterogeneous porous media. Water Resour. Res. 51, 261-280.

https://doi.org/10.1002/2014WR015330

Chiogna, G., Eberhardt, C., Grathwohl, P., Cirpka, O.A., Rolle, M., 2010. Evidence of compound-dependent hydrodynamic and mechanical transverse dispersion by multitracer laboratory experiments. Environ.

Sci. Technol. 44, 688-693.

Cirpka, O.A., Frind, E.O., Helmig, R., 1999. Streamline-oriented grid generation for transport modelling in two-dimensional domains including wells. Adv. Water Resour. 22, 697-710.

https://doi.org/10.1016/S0309-1708(98)00050-5

Davis, T.A., Duff, I.S., 1997. An Unsymmetric-Pattern Multifrontal Method for Sparse LU Factorization. SIAM J. Matrix Anal. Appl. 18, 140-158. https://doi.org/10.1137/S0895479894246905

Descourvières, C., Hartog, N., Patterson, B.M., Oldham, C., Prommer, H., 2010a. Geochemical controls on sediment reactivity and buffering processes in a heterogeneous aquifer. Appl. Geochemistry 25, 261275. https://doi.org/10.1016/j.apgeochem.2009.11.012

Descourvières, C., Prommer, H., Oldham, C., Greskowiak, J., Hartog, N., 2010b. Kinetic Reaction Modeling Framework for Identifying and Quantifying Reductant Reactivity in Heterogeneous Aquifer Sediments 44, 6698-6705. https://doi.org/10.1021/es101661u

Donaldson, J.H., Istok, J.D., Humphrey, M.D., O’Reilly, K.T., Hawelka, C.A., Mohr, D.H., 1997. 
Development and Testing of a Kinetic Model for Oxygen Transport in Porous Media in the Presence of Trapped Gas. Ground Water 35, 270-279. https://doi.org/10.1111/j.1745-6584.1997.tb00084.x

Englert, A., Hubbard, S.S., Williams, K.H., Li, L., Steefel, C.I., 2009. Feedbacks between hydrological heterogeneity and bioremediation induced biogeochemical transformations. Environ. Sci. Technol. 43, 5197-5204. https://doi.org/10.1021/es803367n

Fakhreddine, S., Lee, J., Kitanidis, P.K., Fendorf, S., Rolle, M., 2016. Imaging geochemical heterogeneities using inverse reactive transport modeling: An example relevant for characterizing arsenic mobilization and distribution. Adv. Water Resour. 88, 186-197. https://doi.org/10.1016/J.ADVWATRES.2015.12.005

Galán, E., Gómez-Ariza, J.L., González, I., Fernández-Caliani, J.C., Morales, E., Giráldez, I., 2003. Heavy metal partitioning in river sediments severely polluted by acid mine drainage in the Iberian Pyrite Belt. Appl. Geochemistry 18, 409-421. https://doi.org/10.1016/S0883-2927(02)00092-6

Gerke, H.H., Molson, J.W., Frind, E.O., 2001. Modelling the impact of physical and chemical heterogeneity on solute leaching in pyritic overburden mine spoils. Ecol. Eng. 17, 91-101. https://doi.org/10.1016/S0925-8574(00)00150-6

Gerke, H.H., Molson, J.W., Frind, E.O., 1998. Modelling the effect of chemical heterogeneity on acidification and solute leaching in overburden mine spoils. J. Hydrol. 209, 166-185. https://doi.org/10.1016/S0022-1694(98)00106-1

Guedes de Carvalho, J.R.F., Delgado, J.M.P.Q., 2005. Overall map and correlation of dispersion data for flow through granular packed beds. Chem. Eng. Sci. 60, 365-375. https://doi.org/10.1016/J.CES.2004.07.121

Haberer, C.M., Muniruzzaman, M., Grathwohl, P., Rolle, M., Grathwohl, P., 2015a. Diffusive-Dispersive and Reactive Fronts in Porous Media: Iron(II) Oxidation at the Unsaturated-Saturated Interface. Vadose Zo. J. 0, 0. https://doi.org/10.2136/yzj2014.07.0091

Haberer, C.M., Rolle, M., Cirpka, O.A., Grathwohl, P., 2015b. Impact of Heterogeneity on Oxygen Transfer in a Fluctuating Capillary Fringe. Groundwater 53, 57-70. https://doi.org/10.1111/gwat.12149

Haberer, C.M., Rolle, M., Cirpka, O.A., Grathwohl, P., 2012. Oxygen Transfer in a Fluctuating Capillary Fringe. Vadose Zo. J. 11, 0. https://doi.org/10.2136/vzj2011.0056

Haberer, C.M., Rolle, M., Liu, S., Cirpka, O.A., Grathwohl, P., 2011. A high-resolution non-invasive approach to quantify oxygen transport across the capillary fringe and within the underlying groundwater. J. Contam. Hydrol. 122, 26-39. https://doi.org/10.1016/j.jconhyd.2010.10.006

Hartog, N., Griffioen, J., Van der Weijden, C.H., 2002. Distribution and reactivity of O2-reducing components in sediments from a layered aquifer. Environ. Sci. Technol. 36, 2338-2344. https://doi.org/10.1021/es015681s

Hochstetler, D.L., Rolle, M., Chiogna, G., Haberer, C.M., Grathwohl, P., Kitanidis, P.K., 2013. Effects of compound-specific transverse mixing on steady-state reactive plumes: Insights from pore-scale simulations and Darcy-scale experiments. Adv. Water Resour. 54, 1-10. https://doi.org/10.1016/j.advwatres.2012.12.007 
Jessen, S., Postma, D., Thorling, L., Müller, S., Leskelä, J., Engesgaard, P., 2017. Decadal variations in groundwater quality: A legacy from nitrate leaching and denitrification by pyrite in a sandy aquifer. Water Resour. Res. 53, 184-198. https://doi.org/10.1002/2016WR018995

Jones, G.W., Pichler, T., 2007. Relationship between Pyrite Stability and Arsenic Mobility During Aquifer Storage and Recovery in Southwest Central Florida. Environ. Sci. Technol. 41, 723-730. https://doi.org/10.1021/es061901w

Jørgensen, N.O., Andersen, M.S., Engesgaard, P., 2008. Investigation of a dynamic seawater intrusion event using strontium isotopes (87Sr/86Sr). J. Hydrol. 348, 257-269. https://doi.org/10.1016/j.jhydrol.2007.10.001

Jost, D., Winter, J., Gallert, C., 2011. Water and Oxygen Dependence of Growing in Silica Sand Capillary Fringes. Vadose Zo. J. 10, 532. https://doi.org/10.2136/vzj2010.0092

Jung, H., Navarre-Sitchler, A., 2018. Scale effect on the time dependence of mineral dissolution rates in physically heterogeneous porous media. Geochim. Cosmochim. Acta 234, 70-83. https://doi.org/10.1016/J.GCA.2018.05.009

Kinniburgh, D.G., Gale, I.N., Smedley, P.L., Darling, W.G., West, J.M., Aldous, P.J., O’Shea, M.J., 1994. The effects of historic abstraction of groundwater from the London Basin aquifers on groundwater quality. Appl. Geochemistry 9, 175-195. https://doi.org/10.1016/0883-2927(94)90006-X

Klimant, I., Wolfbeis, O.S., 1995. Oxygen-sensitive luminescent materials based on silicone-soluble ruthenium diimine complexes. Anal. Chem. 67, 3160-3166.

Kocar, B.D., Polizzotto, M.L., Benner, S.G., Ying, S.C., Ung, M., Ouch, K., Samreth, S., Suy, B., Phan, K., Sampson, M., Fendorf, S., 2008. Integrated biogeochemical and hydrologic processes driving arsenic release from shallow sediments to groundwaters of the Mekong delta. Appl. Geochemistry 23, 30593071. https://doi.org/10.1016/j.apgeochem.2008.06.026

Larsen, F., Postma, D., 1997. Nickel mobilization in a groundwater well field: Release by pyrite oxidation and desorption from manganese oxides. Environ. Sci. Technol. 31, 2589-2595. https://doi.org/10.1021/es9610794

Lazareva, O., Druschel, G., Pichler, T., 2015. Understanding arsenic behavior in carbonate aquifers: Implications for aquifer storage and recovery (ASR). Appl. Geochemistry 52, 57-66. https://doi.org/10.1016/j.apgeochem.2014.11.006

Li, L., Gawande, N., Kowalsky, M.B., Steefel, C.I., Hubbard, S.S., 2011. Physicochemical Heterogeneity Controls on Uranium Bioreduction Rates at the Field Scale. Environ. Sci. Technol. 45, 9959-9966. https://doi.org/10.1021/es201111y

Li, L., Salehikhoo, F., Brantley, S.L., Heidari, P., 2014. Spatial zonation limits magnesite dissolution in porous media. Geochim. Cosmochim. Acta 126, 555-573.

Manaka, M., Takeda, M., 2016. Consumption and diffusion of dissolved oxygen in sedimentary rocks. J. Contam. Hydrol. 193, 35-47. https://doi.org/10.1016/j.jconhyd.2016.08.007

McNeece, C.J., Hesse, M.A., 2017. Challenges in Coupling Acidity and Salinity Transport in Porous Media. Environ. Sci. Technol. 51, 11799-11808. https://doi.org/10.1021/acs.est.7b02318 
McNeece, C.J., Hesse, M.A., 2016. Reactive transport of aqueous protons in porous media. Adv. Water Resour. 97, 314-325. https://doi.org/10.1016/J.ADVWATRES.2016.09.013

Muniruzzaman, M., Haberer, C.M., Grathwohl, P., Rolle, M., 2014. Multicomponent ionic dispersion during transport of electrolytes in heterogeneous porous media: Experiments and model-based interpretation. Geochim. Cosmochim. Acta 141, 656-669. https://doi.org/10.1016/J.GCA.2014.06.020

Muniruzzaman, M., Rolle, M., 2016. Modeling multicomponent ionic transport in groundwater with IPhreeqc coupling: Electrostatic interactions and geochemical reactions in homogeneous and heterogeneous domains. Adv. Water Resour. 98, 1-15. https://doi.org/10.1016/J.ADVWATRES.2016.10.013

Nardi, A., Idiart, A., Trinchero, P., de Vries, L.M., Molinero, J., 2014. Interface COMSOL-PHREEQC (iCP), an efficient numerical framework for the solution of coupled multiphysics and geochemistry. Comput. Geosci. 69, 10-21. https://doi.org/10.1016/J.CAGEO.2014.04.011

Neil, C.W., Yang, Y.J., Schupp, D., Jun, Y.-S., 2014. Water Chemistry Impacts on Arsenic Mobilization from Arsenopyrite Dissolution and Secondary Mineral Precipitation: Implications for Managed Aquifer Recharge. Environ. Sci. Technol. 48, 4395-4405. https://doi.org/10.1021/es405119q

Parkhurst, D.L., Appelo, C.A.J., 2013. Description of Input and Examples for PHREEQC Version 3 - A Computer Program for Speciation, Batch-Reaction, One-Dimensional Transport, and Inverse Geochemical Calculations, in: Groundwater Book 6, Modeling Techniques. U.S. Geological Survey, USA, p. Techniques and Methods 6-A43.

Postma, D., Boesen, C., Kristiansen, H., Larsen, F., 1991. Nitrate Reduction in an Unconfined Sandy Aquifer: Water Chemistry, Reduction Processes, and Geochemical Modeling. Water Resour. Res. 27, 2027-2045. https://doi.org/10.1029/91WR00989

Price, R.E., Pichler, T., 2006. Abundance and mineralogical association of arsenic in the Suwannee Limestone (Florida): Implications for arsenic release during water-rock interaction. Chem. Geol. 228, 44-56. https://doi.org/10.1016/j.chemgeo.2005.11.018

Prommer, H., Barry, D., Zheng, C., 2003. MODFLOW/MT3DMS $\square$ Based Reactive Multicomponent Transport Modeling. Groundwater.

Prommer, H., Stuyfzand, P.J., 2005. Identification of Temperature-Dependent Water Quality Changes during a Deep Well Injection Experiment in a Pyritic Aquifer. Environ. Sci. Technol. 39, 2200-2209. https://doi.org/10.1021/es0486768

Rimstidt, D.D., Vaughan, D.J., 2003. Pyrite oxidation: A state-of-the-art assessment of the reaction mechanism. Geochim. Cosmochim. Acta 67, 873-880. https://doi.org/10.1016/S0016-7037(02)01165-1

Rolle, M., Chiogna, G., Bauer, R., Griebler, C., Grathwohl, P., 2010. Isotopic Fractionation by Transverse Dispersion: Flow-through Microcosms and Reactive Transport Modeling Study. Environ. Sci. Technol. 44, 6167-6173. https://doi.org/10.1021/es101179f

Rolle, M., Chiogna, G., Hochstetler, D.L., Kitanidis, P.K., 2013a. On the importance of diffusion and compound-specific mixing for groundwater transport: An investigation from pore to field scale. J. Contam. Hydrol. 153, 51-68. https://doi.org/10.1016/j.jconhyd.2013.07.006 
Rolle, M., Eberhardt, C., Chiogna, G., Cirpka, O.A., Grathwohl, P., 2009. Enhancement of dilution and transverse reactive mixing in porous media: Experiments and model-based interpretation. J. Contam. Hydrol. 110, 130-142. https://doi.org/10.1016/J.JCONHYD.2009.10.003

Rolle, M., Hochstetler, D., Chiogna, G., Kitanidis, P.K., Grathwohl, P., 2012. Experimental Investigation and Pore-Scale Modeling Interpretation of Compound-Specific Transverse Dispersion in Porous Media. Transp. Porous Media 93, 347-362. https://doi.org/10.1007/s11242-012-9953-8

Rolle, M., Muniruzzaman, M., Haberer, C.M., Grathwohl, P., 2013b. Coulombic effects in advectiondominated transport of electrolytes in porous media: Multicomponent ionic dispersion. Geochim. Cosmochim. Acta 120, 195-205. https://doi.org/10.1016/j.gca.2013.06.031

Rolle, M., Sprocati, R., Masi, M., Jin, B., Muniruzzaman, M., 2018. Nernst-Planck-based Description of Transport, Coulombic Interactions, and Geochemical Reactions in Porous Media: Modeling Approach and Benchmark Experiments. Water Resour. Res. 54, 3176-3195. https://doi.org/10.1002/2017WR022344

Salehikhoo, F., Li, L., 2015. The role of magnesite spatial distribution patterns in determining dissolution rates: When do they matter? Geochim. Cosmochim. Acta 155, 107-121. https://doi.org/10.1016/j.gca.2015.01.035

Sánchez España, J., López Pamo, E., Santofimia, E., Aduvire, O., Reyes, J., Barettino, D., 2005. Acid mine drainage in the Iberian Pyrite Belt (Odiel river watershed, Huelva, SW Spain): Geochemistry, mineralogy and environmental implications. Appl. Geochemistry 20, 1320-1356. https://doi.org/10.1016/J.APGEOCHEM.2005.01.011

Schreiber, M.E., Simo, J.A., Freiberg, P.G., 2000. Stratigraphic and geochemical controls on naturally occurring arsenic in groundwater, eastern Wisconsin, USA. Hydrogeol. J. 8, 161-176. https://doi.org/10.1007/PL00021535

Shi, J., Solpuker, U., Kim, Y., Schwartz, F.W., 2013. An experimental investigation of reaction zone controls on fluid flow and mass transport. Appl. Geochemistry 31, 279-291. https://doi.org/10.1016/j.apgeochem.2013.01.016

Soltanian, M.R., Ritzi, R.W., Dai, Z., Huang, C.C., 2015. Reactive solute transport in physically and chemically heterogeneous porous media with multimodal reactive mineral facies: The Lagrangian approach. Chemosphere 122, 235-244. https://doi.org/10.1016/J.CHEMOSPHERE.2014.11.064

Steefel, C.I., DePaolo, D.J., Lichtner, P.C., 2005. Reactive transport modeling: An essential tool and a new research approach for the Earth sciences, Earth and Planetary Science Letters. https://doi.org/10.1016/j.epsl.2005.09.017

Stollenwerk, K.G., 1994. Geochemical interactions between constituents in acidic groundwater and alluvium in an aquifer near Globe, Arizona. Appl. Geochemistry 9, 353-369. https://doi.org/10.1016/08832927(94)90058-2

Vaclavkova, S., Schultz-Jensen, N., Jacobsen, O.S., Elberling, B., Aamand, J., 2015. Nitrate-Controlled Anaerobic Oxidation of Pyrite by Thiobacillus Cultures. Geomicrobiol. J. 32, 412-419. https://doi.org/10.1080/01490451.2014.940633

Vieweg, M., Trauth, N., Fleckenstein, J.H., Schmidt, C., 2013. Robust optode-based method for measuring 
in situ oxygen profiles in gravelly streambeds. Environ. Sci. Technol. 47, 9858-9865. https://doi.org/10.1021/es401040w

Walker, F.P., Schreiber, M.E., Rimstidt, J.D., 2006. Kinetics of arsenopyrite oxidative dissolution by oxygen. Geochim. Cosmochim. Acta 70, 1668-1676. https://doi.org/10.1016/j.gca.2005.12.010

Wallis, I., Prommer, H., Simmons, C.T., Post, V., Stuyfzand, P.J., 2010. Evaluation of Conceptual and Numerical Models for Arsenic Mobilization and Attenuation during Managed Aquifer Recharge. Environ. Sci. Technol. 44, 5035-5041. https://doi.org/10.1021/es100463q

Wen, H., Li, L., 2018. An upscaled rate law for mineral dissolution in heterogeneous media: The role of time and length scales. Geochim. Cosmochim. Acta 235, 1-20. https://doi.org/10.1016/j.gca.2018.04.024

Williamson, M.A., Rimstidt, J.D.D., 1994. The kinetics and electrochemical rate-determining step of aqueous pyrite oxidation. Geochim. Cosmochim. Acta 58, 5443-5454. https://doi.org/10.1016/00167037(94)90241-0

Wissmeier, L., Barry, D.A.A., 2011. Simulation tool for variably saturated flow with comprehensive geochemical reactions in two- and three-dimensional domains. Environ. Model. Softw. 26, 210-218. https://doi.org/10.1016/j.envsoft.2010.07.005

Ye, Y., Chiogna, G., Cirpka, O., Grathwohl, P., Rolle, M., 2015a. Experimental investigation of compoundspecific dilution of solute plumes in saturated porous media: 2-D vs. 3-D flow-through systems. J. Contam. Hydrol. 172, 33-47. https://doi.org/10.1016/j.jconhyd.2014.11.002

Ye, Y., Chiogna, G., Cirpka, O.A., Grathwohl, P., Rolle, M., 2015b. Enhancement of plume dilution in twodimensional and three-dimensional porous media by flow focusing in high-permeability inclusions. Water Resour. Res. 51, 5582-5602. https://doi.org/10.1002/2015WR016962

Ye, Y., Chiogna, G., Cirpka, O.A.A., Grathwohl, P., Rolle, M., 2015c. Experimental Evidence of Helical Flow in Porous Media. Phys. Rev. Lett. 115, 194502. https://doi.org/10.1103/PhysRevLett.115.194502

Zhu, C., Schwartz, F.W., 2011. Hydrogeochemical processes and controls on water quality and water management. Elements 7, 169-174. https://doi.org/10.2113/gselements.7.3.169

Ziegler, B.A., Schreiber, M.E., Cozzarelli, I.M., 2017. The role of alluvial aquifer sediments in attenuating a dissolved arsenic plume. J. Contam. Hydrol. 204, 90-101. https://doi.org/10.1016/j.jconhyd.2017.04.009 
Fig. 1. Experimental laboratory setups for the investigation of pyrite oxidation: (a) batch experiments, (b) 1-D column experiments, (c) 2-D flow-through experiments. Different colors of the inclusions represent their different composition, dark gray: pure pyrite inclusion, light gray: pyrite mixed with sand.

Fig. 2. Observed (symbols) and simulated (lines) concentrations of reactants and products in the two series of batch experiments performed with different agitation.

Fig. 3. Observed (symbols) and simulated (lines) breakthrough curves of $\mathrm{O}_{2}$ in the conservative column experiment at two different locations: $x=7.5 \mathrm{~cm}$ and $x=12.5 \mathrm{~cm}$. The dotted lines represent the simulated $\mathrm{O}_{2}$ breakthrough with no gas partitioning.

Fig. 4. Spatial profiles of oxygen concentration measured during the reactive experiments in the three chemically heterogeneous column setups (the grey areas show the reactive pyrite inclusions; the different colors of the inclusions represent their different composition, dark gray: pure pyrite inclusion, light gray: pyrite mixed with sand).

Fig. 5. Comparison between observed (symbols) and simulated (lines) $\mathrm{O}_{2}$ spatial profiles in Column 1 (a-d), Column 2 (e-h) and Column 3 (i-l) at different time steps. The gray areas show the location of the reactive pyrite inclusions; the different colors of the inclusions represent their different composition, dark gray: pure pyrite inclusion, light gray: pyrite mixed with sand.

Fig. 6. Observed (symbols) and simulated (lines) breakthrough curves of $\mathrm{Fe}, \mathrm{S}$ (a-c) and $\mathrm{O}_{2}$ (d-f) for the column experiments: Column 1 (a,d), Column 2 (b,e), and Column 3 (c,f). Fe and S breakthrough curves were measured at the outlet of the column, whereas the oxygen breakthrough was measured at $\mathrm{x}=11.75 \mathrm{~cm}$.

Fig. 7. Simulated spatial distributions of (a) $\mathrm{O}_{2}$ concentration (b), pyrite content (b), and (c) $\mathrm{FeOOH}$ precipitate in the 2-D flow-through chamber after 98 hours.

Fig. 8. Fig. 8. Experimental (symbols) and simulated (lines) O2 concentration profiles at the four sensors strips locations $(x=16,32,48$, and $64 \mathrm{~cm})$ in the 2-D flow-through chamber at different times. 
Fig. 9. Measured (symbols) and simulated (lines) vertical profiles of Fe (a), S (b), pH (c) at the outlet of the 2-D flow-through chamber after $\mathrm{t}=98$ hours.

Fig. 10. Oxygen breakthrough curves measured on the last oxygen sensor strip $(x=64 \mathrm{~cm})$ in the 2D flow-through chamber. The squares and the solid line represent measurements and simulation at the height of the pyrite inclusion, whereas the circles and the dashed line are the observation and simulation outside the inclusion. 
Fig. 1. Observed (symbols) and simulated (lines) concentrations of reactants and products in the two series of batch experiments performed with different agitation: (a) Batch 1 and (b) Batch 2 . 


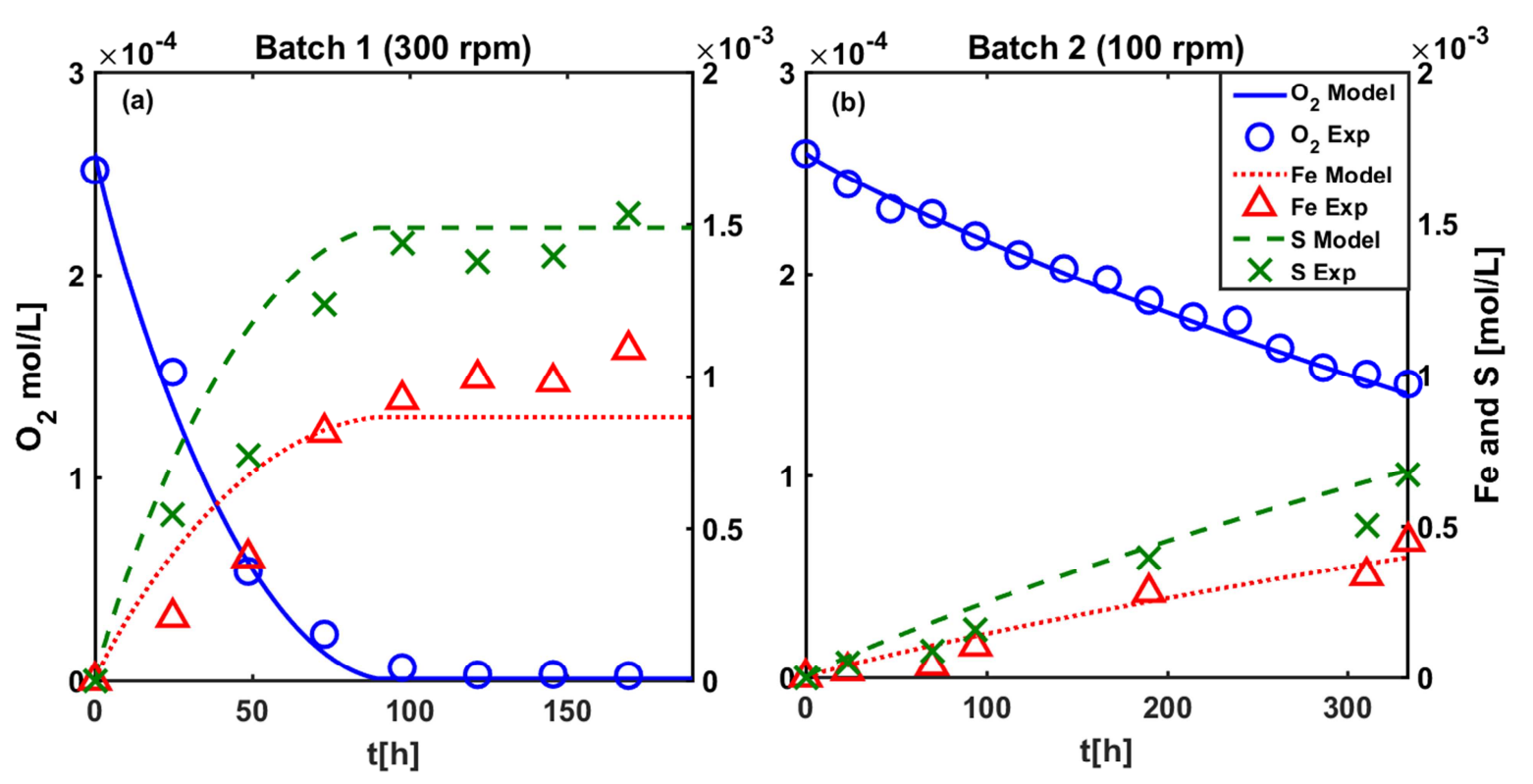




\section{Highlights}

- Pyrite oxidation investigated in multidimensional porous media

- Flow-through experiments in chemically heterogeneous setups

- High-resolution spatial and temporal monitoring of reactive fronts

- Quantitative, model-based interpretation of the pyrite oxidation experiments 